\title{
Central Bank Digital Currency and Banking*
}

\author{
Jonathan Chiu Mohammad Davoodalhosseini \\ Bank of Canada \\ Bank of Canada \\ Janet Jiang \\ $\mathrm{Yu} \mathrm{Zhu}$ \\ Bank of Canada \\ Bank of Canada
}

February 8, 2019

\begin{abstract}
This paper builds a model with imperfect competition in the banking sector. In the model, banks issue deposits and make loans, and deposits can be used as payment instruments by households. We use the model to assess the general equilibrium effects of introducing central bank digital currency (CBDC). We identify a new channel through which CBDC can improve the efficiency of bank intermediation and increase lending and aggregate output even if its usage is low, i.e., CBDC serves as an outside option for households, thus limiting banks' market power in the deposit market. We then calibrate the model to evaluate the quantitative implication of this channel.
\end{abstract}

Keywords: Central Bank Digital Currency, Bank Intermediation/Disintermediation, Imperfect Competition.

JEL Codes: E50, E58.

${ }^{*}$ The views expressed in this paper are those of the authors and not necessarily the views of the Bank of Canada. 


\section{Introduction}

Many central banks are assessing the possibility of introducing widely accessible Central Bank Digital Currency (CBDC) into their economies. ${ }^{1}$ Issuing CBDC would have implications for monetary policy and banking. One concern is that CBDC might crowd out bank deposits, increase banks' funding costs, and reduce lending and investment, i.e., bank disintermediation. This concern is highlighted in the report on CBDC from the Bank for International Settlement, which argues that "... a flow of retail deposits into a CBDC could lead to a loss of low-cost and stable funding for banks, with the size of such a loss in normal times depending on the convenience and costs of the CBDC. Banks could try to prevent a loss of deposits by raising interest rates or seek funding to replace such outflows, e.g., through wholesale funds and term deposits, which would likely be more costly." 2 The IMF staff discussion note by Mancini-Griffoli et al. (2018) also argues that "As some depositors leave banks in favor of CBDC, banks could increase deposit interest rates to make them more attractive. But the higher deposit rates would reduce banks' interest margins. As a result, banks would attempt to increase lending rates, though at the cost of loan demand."

The goal of his paper is to formally assess the effects of CBDC on banking. We develop a tractable model where cash and bank deposits are both used as means of payments. Banks take deposits from households and offer loans to firms to finance projects. Banks' liabilities (deposits) serve as means of payments. In other words, banks perform liquidity transformation by converting illiquid loans into liquid deposits. ${ }^{3}$ We then introduce a widely accessible CBDC into this economy and study

\footnotetext{
${ }^{1}$ For reasons and arguments for issuing CBDC, see Engert and Fung (2017) and references therein.

${ }^{2}$ See BIS report by Committee on Payments and Market Infrastructures (2018).

${ }^{3}$ Such market structure can arise due to information and commitment frictions. Because of these frictions, credit is imperfect. Households need to bring means of payment for consumption. Similarly, firms cannot directly borrow from households because they cannot commit to repay. Banks have enforcement technology and can commit to honor their obligations. Therefore, it
} 
its implications on bank funding cost, lending, investment and output. The model allows us to study various forms of CBDC: whether it is interest bearing or not, whether it is a substitute for bank deposits or cash and whether banks can hold CBDC, and if yes, whether it can be used to satisfy reserve requirements. We show that effects of CBDC on the banking system depends on the competition level in the deposit market and the interest rate on CBDC.

In general, $\mathrm{CBDC}$ with a sufficiently high interest rate has a negative effect on lending. Intuitively, if the CBDC rate is sufficiently high, banks can only compensate for the rising funding cost by raising lending rate, which would lead to a reduction in lending. This happens regardless of the competition level in the deposit market. If the deposit market is not perfectly competitive, a moderate interest rate on CBDC increases bank deposits and lending. In this case, CBDC limits banks' market power and forces them to offer depositors better rates, which attract more deposits and reduce bank profits per unit of deposits. Banks are willing to accommodate the increased deposit demand because they still make a profit per unit of deposits. This leads to more bank funding and in turn leads to more supply of loans and lower lending rates.

Interestingly, CBDC can improve lending even if it is not used in equilibrium. CBDC serves as a viable outside option to bank deposits and hence disciplines the behavior of banks. As a result, the demand for bank deposits becomes more elastic with respect to the deposit rate. Our model has the extreme version: deposits are perfectly elastic at the point of CBDC rate. Therefore, CBDC rate becomes a floor on the deposit rate regardless whether CBDC is used or not. ${ }^{4}$ This insight is closely can channel funds from households to firms and provide payment services. We abstract from consumption loan and focus on commerical loans.

${ }^{4}$ This also suggests that CBDC rate may be a better monetary policy because it transmits directly to the deposit rate. The current monetary policy instruments do not seem to affect depost rates much. For example, the policy rate in the US has increased by $2 \%$ from 2016 to 2018 , but the commercial banks have barely moved the deposit rates, measured as national rate on non-jumbo deposits (less than $\$ 100,000$ ) for money market, savings or interest checking accounts. Data Source: FRED2. 
related to Lagos and Zhang (2018) who show that monetary policy can be effective even if money is not used in the equilibrium because monetary policy changes the value of the outside option and disciplines the equilibrium. The implication of this is that effectiveness of CBDC should be assessed based on its effect on deposits or deposit rate instead of its usage.

We then calibrate the model to the US economy and assess the importance of our mechanism. Results from our benchmark calibration show that: (1) with a proper interest rate, CBDC can raise bank lending and investment substantially $(6 \%) ;(2)$ there is a wide interval of CBDC rates (between $0.05 \%$ and $2.25 \%$ ) at which introducing CBDC increases lending; (3) Introducing CBDC can result in a maximum $1 \%$ output increase. We also study welfare implications of CBDC. An alternative calibration shows that (1) and (2) are qualitatively robust to calibration methods.

There are a few papers that study the effects of CBDC on the banking. Keister and Sanches (2018) consider a perfectly competitive banking sector and show that CBDC can only reduce bank lending. In contrast, our model extends theirs to allow for imperfectly competitive banking sector and show CBDC can increase bank lending. ${ }^{5}$ Andolfatto (2018), in constrast, considers an economy with a monopolistic commercial bank and shows that CBDC may have a positive effect on bank deposits but no impact on bank lending if the central bank lends to the commercial bank. This paper shows that CBDC can have a positive impact on both deposits and lending even if the central bank does not lend to the commercial banks and there

Relatedly, Berentsen and Schar (2018) argue that CBDC makes the monetary policy more transparent. In particular, if CBDC is publicly accessible, its interest rate would be the lowest rate in the economy.

${ }^{5}$ Perfect competition is a limiting case where the number of banks goes to infinity. The key insight is that the market structure is important when assessing the effect of CBDC on bank intermediation. If the banking sector is imperfectly competitive, CBDC increases bank intermediation if its rate is in an intermediate range but causes disintermediation if its rate is above that intermediate range. This range shrinks as the number of banks increases and we obtain the same result as the number of banks approaches infinity. 
are multiple banks. In terms of methodology, Andolfatto (2018) is based on overlapping generation model and this paper follows Lagos and Wright (2005).

Brunnermeier and Niepelt (2018) derive conditions under which the issuance of inside money and outside money are equivalent, even if inside money and outside money have liquidity or return differences. Their results imply that introducing CBDC does not necessarily change macroeconomic outcomes. Barrdear and Kumhof (2016) use a rich DSGE model and estimate that issuing CBDC could increase GDP by up to $3 \%$ through reducing real interest rates. ${ }^{6}$

In general, this paper contributes to the literature on New Monetarist models. Berentsen, Camera and Waller (2008) first incorporate banking to the Lagos and Wright (2005). Our model differs from their work in two dimensions. First, banks in our model engage in imperfect competition. Second, our banks create inside money by taking deposits. We provide conditions under which a monetary equilibrium exists and is unique. We also show that the model can have multiple equilibria under certain parameters, implying that the banking sector can introduce instability into the economy. This point is also made in Gu et al. (2018).

The key mechanism of this paper depends crucially on the market power of banks in the deposit market. Dreschler, Savov and Schnabl (2017) provide empirical evidence that banks have market power in deposit market and explore its implication on monetary policy transmission. Dreschle, Savov and Schnabl (2018) study the effect of this market power on maturity transformation and interest rate risk. Kurlat (2018) shows that this market power raises the cost of inflation.

This rest of the paper is organized as follows. Section 2 introduces the baseline

\footnotetext{
${ }^{6}$ Other papers on e-money and digital currency include Davoodalhosseini (2018), Zhu and Hendry (2018), and Schilling and Uhlig (2018). This paper have many similarities with Zhu and Hendry (2018), which studies the behavior of a monopolistic e-money issuer. This paper studies behaviors of banks who have monopoly power and issues deposits, which can be used for payment. For further reference on e-money and digital currency, see Davoodalhosseini (2018), Davoodalhosseini and Rivadenyra (2018), Engert and Fung (2017), Fung and Halaburda (2016), Kahn, Rivadeneyra, and Wong (2018), Mancini-Griffoli et al. (2018), Zhu and Hendry (2018), and references therein.
} 
model, where there is no CBDC. Section 3 derives the equilibrium of the baseline model. Section 4 considers CBDC with three different designs and studies its implications on the equilibrium under each design. Section 5 calibrates the model and assesses the quantitative implications and Section 6 concludes. Extensions and some omitted proofs are collected in the appendix.

\section{Environment}

The model follows a version of Lagos and Wright (2005) that is studied in Zhu and Hendry (2018). Time is discrete and continues forever. There is a continuum of households with measure 2, a continuum of entrepreneurs with measure $N^{E}$ and $N$ bankers. Here $N$ is an integer. As in the standard New Monetarist model, at each date $t$, agents interact sequentially in two settings: a frictional decentralized market (DM); and a frictionless centralized market $(\mathrm{CM})$. There are two types of good. A numeraire good $x$ produced in the CM and a good $y$ produced in the DM. Both goods are perishable. There is a durable and intrinsically worthless object issued by the government, i.e. fiat money. Its supply at time $t$ is $M_{t}$. The bankers also issue deposits to the households.

Households are divided into two permanent types, i.e. buyers and sellers, each with measure 1 . In the CM, both types work, consume $x$, and determine their positions in fiat money and bank deposits. Their labor $h$ is translate to $x$ one-forone. In the DM, the buyers want to consume $y$, which can be produced on spot by the sellers. Then, buyers and sellers meet and trade bilaterally. Because of anonymity and lack of commitment, credit is not viable. To facilitate the trade, buyers can use fiat money. In addition, banks can commit to repay and as a result, their deposits can also be used as a means of payment.

There are three types of DM meetings. With $\alpha_{1}$ probability, a buyer gets into a type 1 meeting, where only fiat money can be used. With $\alpha_{2}$ probability, a buyer gets 
into a type 2 meeting, where only bank deposits can be used. With $\alpha_{3}$ probability, a buyer gets into a type 3 meeting, where both can be used. These meetings can be thought of in the following way. Type 1 meetings are transactions in local stores which do not have access to debit cards. Type 2 meetings are online transactions where the buyers and sellers are spatially separated and can only use debit card or bank transfers for payment. Type 3 meetings are at local stores with POS machines and hence both payment methods are accepted. The types of meeting are not revealed until the start of the DM each period. Therefore, buyers hold portfolios of fiat money and bank deposits.

Each period, a measure of $N^{E}$ entrepreneurs are born and they will die in the next CM. They consume $x$ in the next CM and has a linear utility. They are born with investment opportunities and can transform $x$ current CM good to $f(x) \mathrm{CM}$ goods in the next CM. Here $f^{\prime}(0)=\infty, f^{\prime}(\infty)=0, f^{\prime}>0$ and $f^{\prime \prime}<0$. However, they do not have resources and cannot commit to repay households. Therefore, they need to borrow but cannot directly borrow from the households. Similarly, $N$ bankers are born, who will die in the next CM. They want to consume $x$ in the next CM with a linear utility. They do not have resources but can commit to repayment and can also enforce payment. As a result, they can issue deposits, which is a promise to pay back purchase power next period that worths one unit of CM good, and finance the investment opportunities. They also have the technology to provide payment service, i.e. bank deposits can be used in type 2 and type 3 meetings.

In every CM, the newly born bankers issue some deposits to the households in exchange of fiat money and also issue some deposits to entrepreneurs as loans. Then the entrepreneurs use the deposits to buy $x$ from buyers for investment. In the next CM, entrepreneurs sell some of the investment output to get cash and deposits and pay back the loans and retain some output for their own consumption. And then bankers use the loan payment to redeem the deposits hold by the households can 
retain some payment from the entrepreneurs for their own consumption.

The government injects or contracts money supply in the CM. We focus on the case where money supply growth as a constant gross rate $\mu=M_{t+1} / M_{t}$. Using the Fisher's equation we can write the nominal interest rate as $\iota=(1+\mu) / \beta-1$.

\subsection{Households}

A buyer has period utility

$$
\boldsymbol{U}(x, y, h)=U(x)-h+u(y) .
$$

In the $\mathrm{CM}$, he solves

$$
\begin{aligned}
W^{B}(Z, D) & =\max _{x, h, \hat{Z}, \hat{D}}\left\{U(x)-h+\beta V^{B}(\hat{Z}, \hat{D})\right\} \\
\text { st. } x & =h+Z+D+T-\frac{\phi}{\hat{\phi}} \hat{Z}-\psi \hat{D},
\end{aligned}
$$

where $\phi$ and $\hat{\phi}$ are the prices of money in terms of the CM good, $\hat{D}$ is the real value of deposits tomorrow and $\psi \hat{D}$ is the real value of deposits today. Therefore, the real interest rate on deposits is $1 / \psi-1$. As standard, we can substitute out $h$ using the budget equation and obtain

$$
W^{B}(Z, D)=Z+D+T+\max _{x}[U(x)-x]+\max _{\hat{D}, \hat{Z}}\left\{-\frac{\phi}{\hat{\phi}} \hat{Z}-\psi \hat{D}+\beta V^{B}(\hat{Z}, \hat{D})\right\} .
$$

This shows that $W^{B}(Z, D)$ is linear in $Z$ and $D$. The first-order conditions (FOCs) are

$$
\begin{array}{ll}
x: & U^{\prime}(x)=1 \\
\hat{Z}: & \frac{\phi}{\hat{\phi}} \geq \beta V_{1}^{B}(\hat{Z}, \hat{D}), \text { equality if } \hat{Z}>0 \\
\hat{D}: & \psi \geq \beta V_{2}^{B}(\hat{Z}, \hat{D}), \text { equality if } \hat{D}>0
\end{array}
$$

where the subscripts means the derivative with respect to corresponding arguments. Notice that the first-order conditions imply that $\hat{Z}$ and $\hat{D}$ are the same for all buyers. 
The DM problem can be written as

$$
\begin{aligned}
V^{B}(Z, D)= & \alpha_{1}[u \circ Y(Z)-P(Z)]+\alpha_{2}[u \circ Y(D)-P(D)] \\
& +\alpha_{3}[u \circ Y(Z+D)-P(Z+D)]+W^{B}(Z, D),
\end{aligned}
$$

where $Y(\cdot)$ and $P(\cdot)$ are terms of trade which is discussed later.

A seller has period utility

$$
\boldsymbol{U}(x, y, h)=U(x)-h-v(y) .
$$

Because he does not need to consume in the DM, we can assume that $Z=D=0$ without loss of generality. Therefore, his CM problem is

$$
\begin{aligned}
W^{S}(Z, D) & =\max _{x, h}\left\{U(x)-h+\beta V^{S}(0,0)\right\} \\
\text { st. } x & =h+Z+D+T .
\end{aligned}
$$

Again $W^{S}$ is linear in $Z$ and $D$. His DM problem is

$$
\begin{aligned}
V^{S}(0,0)= & \alpha_{1}[P(\tilde{Z})-v \circ Y(\tilde{Z})]+\alpha_{2}[P(\tilde{D})-v \circ Y(\tilde{D})] \\
& +\alpha_{3}[P(\tilde{Z}+\tilde{D})-v \circ Y(\tilde{Z}+\tilde{D})]+W^{S}(0,0),
\end{aligned}
$$

where $\tilde{D}$ and $\tilde{Z}$ are the holdings of the buyer in the meetings.

Upon a meeting, the buyer makes a take-it-or-leave-it offer, which determines the terms of trade $Y(\cdot)$ and $P(\cdot)$. Let $z$ be the total real value of all available payment instruments in a meeting, then the buyer offers

$$
\max _{y, p \leq z}[u(y)-p] \text { s.t } p=v(y) .
$$

For simplicity, assume $v(y)=y$. Then one can show that

$$
Y(z)=\left\{\begin{array}{cc}
z & \text { if } z<y^{*} \\
y^{*} & \text { if } z>y^{*}
\end{array}, P(z)=\left\{\begin{array}{cc}
z & \text { if } z<y^{*} \\
y^{*} & \text { if } z>y^{*}
\end{array},\right.\right.
$$

where $u^{\prime}\left(y^{*}\right)=1$. 
Combing the FOCs of buyers and (1)-2, we obtain the Euler's equations

$$
\begin{aligned}
\frac{\phi}{\beta \hat{\phi}} & \geq \alpha_{1} \lambda(\hat{Z})+\alpha_{3} \lambda(\hat{Z}+\hat{D})+1, \text { equality iff } \hat{Z}>0, \\
\frac{\psi}{\beta} & \geq \alpha_{2} \lambda(\hat{D})+\alpha_{3} \lambda(\hat{Z}+\hat{D})+1, \text { equality iff } \hat{D}>0,
\end{aligned}
$$

where $\lambda(D)=\max \left[u^{\prime}(D)-1,0\right]$ is the liquidity premium. At the steady state, (3)-(4) reduce to

$$
\begin{aligned}
\iota & \geq \alpha_{1} \lambda(Z)+\alpha_{3} \lambda(Z+D), \text { equality iff } Z>0, \\
\frac{\psi}{\beta}-1 & \geq \alpha_{2} \lambda(D)+\alpha_{3} \lambda(Z+D), \text { equality iff } D>0 .
\end{aligned}
$$

Here, (5) defines the aggregate demand for $Z$ as a function of $D$. Given this, (6) defines the aggregate inverse demand function for $D$ given $\iota$, i.e. $\psi=\Psi(D)$. We suppress the dependence of $\Psi$ on $\iota$ to ease notations.

Lemma $1 \Psi(D)$ is decreasing in $D$ and increasing in $\iota$.

Proof. After some straightforward algebra, one can show that

$$
\begin{aligned}
\Psi^{\prime}(D) & =\alpha_{2} \beta \lambda^{\prime}(D)+\frac{\alpha_{1} \alpha_{3} \beta \lambda^{\prime}(Z+D) \lambda^{\prime}(Z)}{\alpha_{1} \lambda^{\prime}(Z)+\alpha_{3} \lambda^{\prime}(Z+D)} \leq 0, \\
\frac{\partial \Psi(D)}{\partial \iota} & =\frac{\alpha_{3} \beta \lambda^{\prime}(Z+D)}{\alpha_{1} \lambda^{\prime}(Z)+\alpha_{3} \lambda^{\prime}(Z+D)} \geq 0 .
\end{aligned}
$$

Notice that the first inequality holds strictly if $D<y^{*}$ while the second inequality holds strictly if $\alpha_{3}>0$ and $Z+D<y^{*}$.

\section{$2.2 \quad$ Entrepreneurs}

The entrepreneurs decide their demand for loans given the loan rate $\rho$. Their problem is

$$
\max _{l}\{f(l)-(1+\rho) l\}
$$

This implies that the inverse loan demand for a firm is $f^{\prime}(l)=1+\rho$. This defines an aggregate inverse loan demand function

$$
L^{d}(\rho)=N^{E} f^{\prime-1}(1+\rho) .
$$


Obviously $L^{d}(\cdot)$ is decreasing.

\subsection{Bankers}

For now, we assume that the lending market is perfectly competitive and banks engage in a Cournot competition in the deposit market. We later on consider the case that both the loan market and the deposit market are not perfectly competitive with a competitive interbank market. Bankers face a reserve requirement. At the end of each CM, the real value of a banker's cash holding must exceed $\chi$ fractions of the total deposits where $\chi$ is set exogenously by the government. In addition, the bankers incur a deposit handling cost $c$ per real value of deposit.

Then banker $j$ chooses $d_{j}, \ell_{j}$ and $z_{j}$ to maximize its utility taking $\rho$ and $d_{-j}=$ $\sum_{i \neq j} d_{i}$ as given.

$$
\begin{aligned}
& \max _{z_{j}, \ell_{j}, d_{j}}\left\{(1+\rho) \ell_{j}+\frac{z_{j}}{\mu}-\left[d_{j}+\Psi\left(d_{-j}+d_{j}\right) d_{j} c\right]\right\} \\
& \text { st } \quad \ell_{j}+z_{j}=\Psi\left(d_{-j}+d_{j}\right) d_{j}, \\
& z_{j} \geq \chi \Psi\left(d_{-j}+d_{j}\right) d_{j} .
\end{aligned}
$$

The banker gets back loan plus interest $(1+\rho) \ell_{j}$, gets the post-inflation value of money holdings, and redeems the deposits $d_{j}$ and pays the deposit handling cost. The first equation in the constraint is the balance sheet identity of the bank at the end of the first CM. The right hand side is the liability, which is the real value of deposits and the left hand side is the asset which includes money and loans. The second constraint reflects the reserve requirement. Using the balance sheet identity and the reserve requirement to substitute out $z_{j}$, one can rewrite the problem as

$$
\begin{gathered}
\max _{z_{j}, \ell_{j}, d_{j}}\left\{\left(1+\rho-\frac{1}{\mu}\right) \ell_{j}-\left[d_{j}+\Psi\left(d_{-j}+d_{j}\right) d_{j} c-\frac{\Psi\left(d_{-j}+d_{j}\right) d_{j}}{\mu}\right]\right\} \\
\text { st } \quad \ell_{j} \leq(1-\chi) \Psi\left(d_{-j}+d_{j}\right) d_{j} .
\end{gathered}
$$

Given each $\rho$, this defines a best response function that maps $d_{-j}$ to $d_{j}$. We look for a symmetric equilibrium where $d_{-j}=\left(N_{b}-1\right) d_{j}$ for every $j$. Once we solve for 
$d_{j}$, we can compute the loan supply at $\rho$. Throughout the paper, we assume that the following holds.

Assumption 1 a) Given any $d_{-j} \in\left[0, y^{*}\right)$ and $\kappa>\beta$, either there exists a unique $d_{j}>0$ such that $\Psi^{\prime}\left(d_{-j}+d\right) d+\Psi\left(d_{-j}+d\right) \gtrless \kappa$ if $d \lessgtr d_{j}$ or $\Psi^{\prime}\left(d_{-j}+d\right) d+$ $\Psi\left(d_{-j}+d\right)<\kappa$ for all $d \geq 0$.

b) In addition, $\Psi^{\prime}(N d) d+\Psi(N d)$ decreases with $d$ on $\left[0, y^{*} / N\right)$.

Part (a) of this assumption is similar to the single crossing condition and states that $\Psi^{\prime}\left(d_{-j}+d\right) d+\Psi\left(d_{-j}+d\right)$ as a function of $d$ should cross the horizontal axis from the above and at most once. We need part (a) to ensure that the best response of banker $j$ to any amount of deposits (less than $y^{*}$ ) created by other banks is unique. We need part (b) to ensure that there is at most one symmetric Nash equilibrium of the Cournot game. One can show that this assumption holds if $v$ is linear, $u$ is CRRA utility with a coefficient less than 1 and $\alpha_{3}=0$. By continuity, this would hold for all $\alpha_{3}$ that is sufficiently small and

$$
u(y)=\frac{(y+\varepsilon)^{1-\sigma}-\varepsilon^{1-\sigma}}{1-\sigma}
$$

with $\sigma<1$ and $\varepsilon$ sufficiently small. Define

$$
\begin{aligned}
\bar{\mu} & =1 /\left[\Psi(0)^{-1}+c\right] \\
\tilde{\rho} & =\left[\frac{1}{\Psi(0)}+c-\frac{1}{\mu}\right](1-\chi)^{-1}+\frac{1}{\mu}-1, \\
\bar{\rho} & =\frac{c+1 / \beta-1+\chi(1-1 / \mu)}{1-\chi} .
\end{aligned}
$$

Here $\bar{\mu}$ is the lowest inflation level at which bankers are unwilling to operate without lending opportunities. If $\mu<\bar{\mu}$, the bankers are willing to supply deposits even if they cannot lend and can only hold money. If $\mu \geq \bar{\mu}$, they stop to operate without lending opportunities because holding cash is too costly. Similarly, $\tilde{\rho}$ is the highest lending rate that bankers are unwilling to operate if they are forced to lend up to 
the reserve requirement. If $\rho>\tilde{\rho}$, bankers supply positive deposits. Notice that if $\mu<\bar{\mu}, \tilde{\rho}<1 / \mu-1$. Lastly, $\bar{\rho}$ is the highest interest at which bankers earn finite profit. If $\rho>\bar{\rho}$, bankers can have unbounded profit by having infinite amount of deposits and loans.

Proposition 1 Under Assumption 1, the following claims hold

1. There is a unique symmetric pure strategy equilibrium in the Cournot game if $\rho<\bar{\rho}$

2. Suppose $\Psi(0)<\infty$ and $\Psi^{\prime}(0)<\infty$. The total deposit $D(\rho)$ satisfies

$$
D(\rho)= \begin{cases}0 & \text { if } \mu>\bar{\mu} \text { and } \rho<\tilde{\rho} \\ N d^{*}(\rho) & \text { if } \rho<\bar{\rho} \text { and } \beta<\mu<\bar{\mu} \\ {\left[\frac{N}{N-1} y^{*}, \infty\right] \cup\left\{N d^{*}(\rho)\right\}} & \text { or } \rho>\tilde{\rho} \text { and } \mu>\bar{\mu} \\ \infty & \text { if } \rho>\bar{\rho}\end{cases}
$$

where

$$
\begin{aligned}
& \Psi^{\prime}\left(N d^{*}(\rho)\right) d^{*}(\rho)+\Psi\left(N d^{*}(\rho)\right)=1 / \xi \\
& \xi=\max \left\{\left(1+\rho-\frac{1}{\mu}\right)(1-\chi), 0\right\}+1 / \mu-c
\end{aligned}
$$

3. $D(\rho)$ is weakly increasing in $\rho$.

Proof. First notice that in the equilibrium there is no deposit iff the best response to $d_{-j}=0$ is $d_{j}=0$. This is true iff

$$
\left[(1-\chi) \max \left\{1+\rho, \frac{1}{\mu}\right\}+\frac{\chi}{\mu}-c\right] \Psi(0)-1<0 .
$$

One can check that this is true iff $\mu>\bar{\mu}$ and $\rho<\tilde{\rho}$. This proves the second claim. Now suppose that $\mu>\bar{\mu}$ and $\rho<\tilde{\rho}$ does not hold, for any $\rho<\bar{\rho}$, banker $j$ 's problem can be rewritten as

$$
\max _{d_{j}} \xi \Psi\left(d_{-j}+d_{j}\right) d_{j}-d_{j}
$$

where $\xi=1 / \mu-c$ if $\rho<1 / \mu-1$ and $\xi=\left(1+\rho-\frac{1}{\mu}\right)(1-\chi)+1 / \mu-c$ if $\rho>1 / \mu-1$.

By Assumption 1, there is a unique solution to this problem. This solution satisfies 
$\Psi^{\prime}\left(d_{-j}+d_{j}\right) d_{j}+\Psi\left(d_{-j}+d_{j}\right)=1 / \xi$ or $d_{j}=0$. Then the symmetric pure strategy Nash equilibrium $d$ must satisfy $\Psi^{\prime}(N d) d+\Psi(N d)=1 / \xi$. Notice that $\Psi(0)>1 / \xi$ and $\Psi\left(y^{*}\right)=\beta<1 / \xi$. Therefore, $\Psi^{\prime}(N d) d+\Psi(N d)<1 / \xi$ for all $d$ that is smaller than but sufficiently close to $y^{*} / N$. Because $\Psi^{\prime}(N d) d+\Psi(N d)$ is continuously decreasing on $\left[0, y^{*} / N\right)$, there exists a unique solution. Therefore, there is a unique symmetric pure strategy equilibrium $d^{*}(\rho)$. The total supply is $D(\rho)=N d^{*}(\rho)$. If $\rho=\bar{\rho}$, there is a unique solution to $\Psi^{\prime}(N d) d+\Psi(N d)=1 / \xi=\beta$ on $\left[0, y^{*} / N\right)$. In addition, this equation holds if $d>y^{*} /(N-1)$. But not all $d>y^{*} /(N-1)$ can be an equilibrium. Because if $d_{-j}=d(N-1)<y^{*}$, banker $j$ 's best response is $d<y^{*}-d(N-1)$, which yields strictly positive profit while $d>y^{*}-d(N-1)$ leads to 0 profit. However, if $d>y^{*} /(N-1)$ can be a symmetric pure strategy equilibrium because no banker has a profitable deviation. Therefore, $D(\rho)=d^{*}(\rho)$ or $D(\rho)>\frac{N}{N-1} y^{*}$. If $\rho>\bar{\rho}$, the best response of banker $j$ is $d_{j}=\infty$. Therefore, $D(\rho)=\infty$. To see the last claim, just notice that by Assumption $1, d^{*}(\rho)$ is increasing.

Corollary 1 The loan supply function is

$$
L^{s}(\rho)= \begin{cases}0 & \text { if } \rho<\frac{1}{\mu}-1 \\ {[0,(1-\chi) D(\rho) \Psi(D(\rho))]} & \text { if } \rho=\frac{1}{\mu}-1 \\ (1-\chi) D(\rho) \Psi(D(\rho)) & \text { if } \rho \in\left(\frac{1}{\mu}-1, \bar{\rho}\right) . \\ \left\{(1-\chi) N d^{*}(\rho) \Psi\left(N d^{*}(\rho)\right)\right\} \cup\left[\frac{(1-\chi) N \beta y^{*}}{N-1}, \infty\right] & \text { if } \rho=\bar{\rho} \\ \infty & \text { if } \rho>\bar{\rho}\end{cases}
$$

Proof. Obviously, if $1+\rho<1 / \mu, \ell_{j}=0$ because it is more profitable for the bankers to hold the fiat money than making loans. As a result, $L^{s}(\rho)=N \ell_{j}=0$. If $1+\rho=1 / \mu$, the banks are indifferent on $\ell_{j} \in\left[0,(1-\chi) \Psi\left(d_{-j}+d_{j}\right) d_{j}\right]$, where $d_{j}$ solves

$$
\max _{d_{j}}\left\{\left(\frac{1}{\mu}-c\right) \Psi\left(d_{-j}+d_{j}\right) d_{j}-d_{j}\right\},
$$

because the inequality constraint is not binding. Then $D(\rho)=N d_{j}$ and $L^{s}(\rho)=$ 
$N \ell_{j} \in[0,(1-\chi) D(\rho) \Psi(D(\rho))]$. If $1 / \mu<1+\rho$, bankers lend out all they can. Then the loan supply can be computed from $D(\rho)$.

This result shows that $L^{s}$ is single valued and continuous if $1 / \mu-1<\rho<1 / \beta-1$ or $\rho<1 / \mu-1$. If $\rho=1 / \mu-1, L^{s}$ may be set-valued but convex. But if $\rho>1 / \mu-1$, $L^{s}$ may be set-valued and not convex. Also notice that because $D(\rho)$ can be 0 even if $\rho>1 / \mu-1$ as shown in Proposition $1, L^{s}(\rho)$ may be 0 even if $\rho>1 / \mu-1$. However, this only happens if the money growth rate is too high, i.e. $\mu>\bar{\mu}$. If $\mu<\bar{\mu}, L^{s}(\rho)>0$ if $\rho>1 / \mu-1$.

\section{Equilibrium}

We focus on the steady state equilibrium. Then the inflation rate equals the money growth rate $\mu$. Any $\rho$ that solves $L^{d}(\rho)=L^{s}(\rho)$ constitutes an equilibrium. We can plot the loan supply and loan demand curves in $\rho-L$ space as in Figure 1 to analyze the equilibrium. For illustration, we focus on the case where both $\Psi(D) D$ and $D(\rho)$ are increasing.

The loan demand curve is strictly decreasing as shown by the solid red line. The loan supply curve is illustrated by the solid blue line. As in the proof, it has two cases. The first case is shown in Figure 1(a), where $\tilde{\rho}<1 / \mu-1$. If $\rho<1 / \mu-1$, the loan supply curve coincides with the the horizontal axis. If $\rho=1 / \mu-1$, banks have positive deposits i.e. $D>0$. They are indifferent between lending and holding cash. Therefore, the loan supply curve is vertical between 0 and $(1-\chi) D(\rho) \Psi(D(\rho))$.

The loan supply curve is strictly increasing on $\left(\frac{1}{\mu}-1, \bar{\rho}\right)$. And if $\rho=\bar{\rho}$, it is vertical again. Obviously, the demand and the supply have one and only one intersection, which implies the existence and uniqueness of steady state equilibrium. Notice that if $\rho=1 / \mu-1$ at the intersection, banks hold voluntary reserves. This is because firms are not very productive and banks choose to not lend up to the limit.

Figure 1(b) plots the second case where $\tilde{\rho}>1 / \mu-1$. The only difference is 


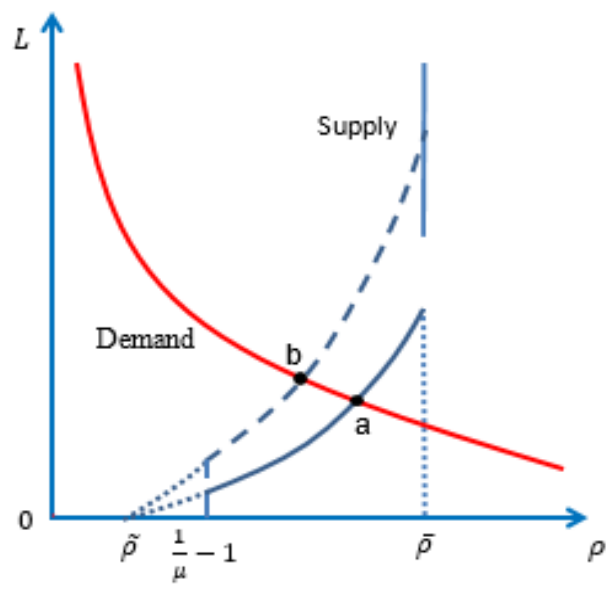

(a) Case 1

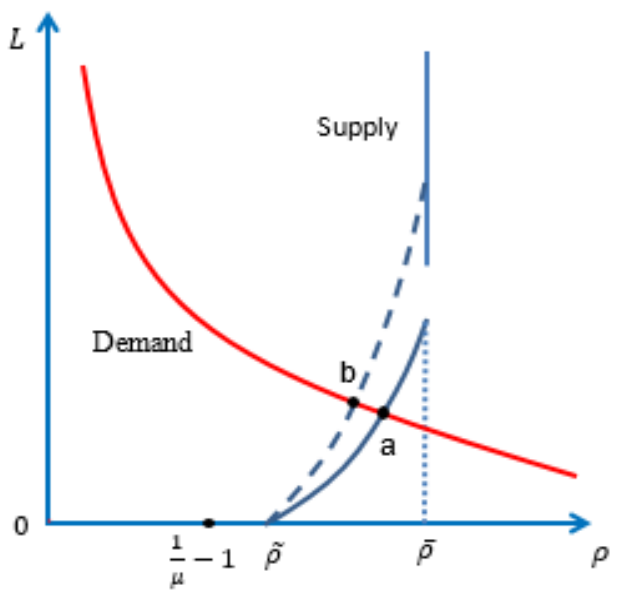

(b) Case 2

Figure 1: Equilibrium with Imperfect Competition

that the supply curve coincides with the horizontal line if $\rho<\tilde{\rho}$. In this case, the demand for liquidity is low. As a result, if the lending rate is too low, the banks are not willing to take deposits and hence loan supply is 0. Again, a steady state equilibrium exists and is unique.

In general, equilibrium may not exist because $L^{s}(\rho)$ may be non-convex valued. And there can be multiple equilibria because $L^{s}(\rho)$ may decrease in some regions. However, one can show that at least one equilibrium exists as long as the productivity is not too high.

Assumption 2 The production function $f$ satisfies $f^{\prime}\left(\frac{(1-\chi) N d^{*}(\bar{\rho}) \Psi\left(N d^{*}(\bar{\rho})\right)}{N^{E}}\right)<1+\bar{\rho}$.

Assumption 2 requires that the productivity is not too high so that $L^{d}$ pass through $L^{s}$ at its continuous part, which guarantees existence of an equilibrium. We also believe this is the relevant case because if the productivity is too high so that Assumption 2 fails, the liquidity premium on deposits vanishes and bankers pay high interests on deposits.

Proposition 2 Under Assumptions 1-2, there exists at least one monetary equilibrium if $\iota$ is not too big. If in addition, $D \Psi(D)$ is increasing in $D$, the equilibrium 
is unique. The equilibrium loan rate is then less than $\bar{\rho}$.

Proof. Notice that $L^{s}(\rho)$ is continuous if $D(\rho)$ is continuous. In addition, $L^{s}(\rho)=0$ for sufficiently small $\rho$ and $\min L^{s}(\bar{\rho})=(1-\chi) N d^{*}(\bar{\rho}) \Psi\left(N d^{*}(\bar{\rho})\right)$. On the other hand, $L^{d}(\rho)$ is decreasing and positive for any $\rho>0$ because $f^{\prime}(0)=$ $\infty$. As a result, $L^{d}(\rho)-L^{s}(\rho)>0$ for $\rho$ sufficiently small and $L^{d}(\bar{\rho})-L^{s}(\bar{\rho})<$ 0 by assumption. In addition, both $L^{d}$ and $L^{s}$ are continuous on $[0, \bar{\rho})$. To see the uniqueness, just notice that on $[0, \bar{\rho}), L^{s}(\rho)$ is increasing and $L^{s}(\rho)$ is strictly decreasing. By the intermediate value theorem, there exists at least one equilibrium with loan rate less than $\bar{\rho}$.

For existence of equilibrium, we require that entrepreneurs are not too productivity such that the loan demand and loan supply curves intersects to the left of $\bar{\rho}$. If this is the case, the buyers are liquidity constrained at least in type 2 meetings.

We can also use the diagrams to analyze comparative statics. For example, if $N$ increases, the solid blue line rotates counter-clockwise to the dashed blue line in Figure 1. Then the equilibrium changes from point $a$ to point $b$. In both cases, the demand intersects the supply in its increasing region. Therefore, loan supply increases and equilibrium $\rho$ decreases. If, however, the intersection is in the vertical part of the supply, equilibrium $\rho$ and $L$ do not change.

Now we analyze the effect of higher inflation $\mu$ or equivalently higher $\iota$. Now we focus on the case where $\mu<\bar{\mu}$. First consider the case where $\alpha_{3}=0$ and $\chi>0$. If $\mu$ increases, the loan demand curve stay unchanged while the loan supply curve changed to the dashed line. In this case, an increase in $\mu$ decreases the demand for fiat money but does not increase the demand for deposits because fiat money and deposits are not substitutes. However, an increase in $\mu$ increases the cost of holding fiat money for the banks. As a result, bankers are willing to lend at a lower loan rate because holding fiat money becomes a less attractive alternative.

But for lending rates at which bankers are willing to lend before the increase 
in the inflation rate $\mu$, the loan supply decreases. This is because it is more costly to satisfy the reserve requirement and the bankers reduces supply of deposit and lending. In Figure 2(a), the equilibrium changes from $a$ to $b$ and there is less lending and higher lending rate. However, if before the change, the bankers hold voluntary reserves as show in Figure 2(b), an increase in $\mu$ increases lending and reduces loan rates because now bankers are more willing to lend.

Now consider the case with $\chi=0$ and $\alpha_{3}>0$. An increase in $\mu$ induces households to substitute out to hold more deposits. This drives up the demand for deposits. Because the bankers do not need to hold reserves, they are willing to increase the supply of deposits and hence increases the supply of loans. This unambiguously increases the equilibrium loan quantity and reduces loan rate as shown in Figure 3(a) and Figure 3(b).

In general, if both $\alpha_{3}$ and $\chi$ are positive, higher inflation can have positive or negative effects on loans depending on which of the above effects dominates. But one can show the following is true.

Proposition 3 If bankers hold voluntary reserves, an increase in $\mu$ increases lending and decreases loan rate.

Proof. In this case, if $\mu$ increases, the loan demand and loan supply curve can only intersects at a point to the left of the current equilibrium on the $\rho$ - $L$ space. Because loan demand is decreasing, this implies that loan rate is lower and loan quantity is higher.

\section{Effects of CBDC}

This section analyzes the effects of an interest-bearing CBDC on bank lending and the real economy. Obviously, the effects of CBDC depend on its design. There are several design dimensions that we can consider using our model: whether CBDC is 


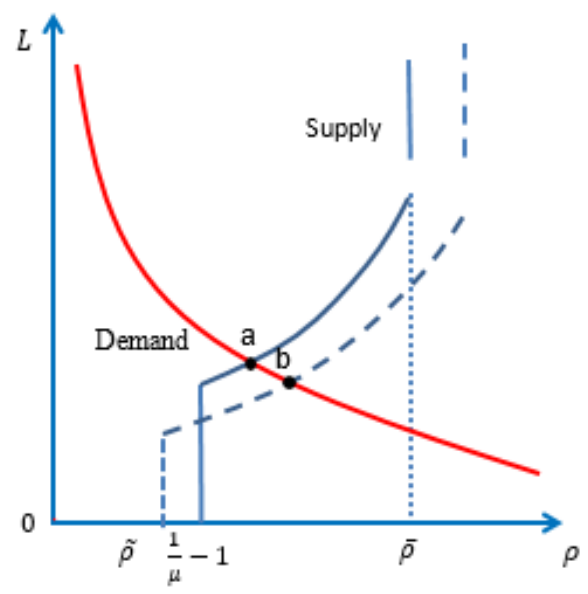

(a) Case 1

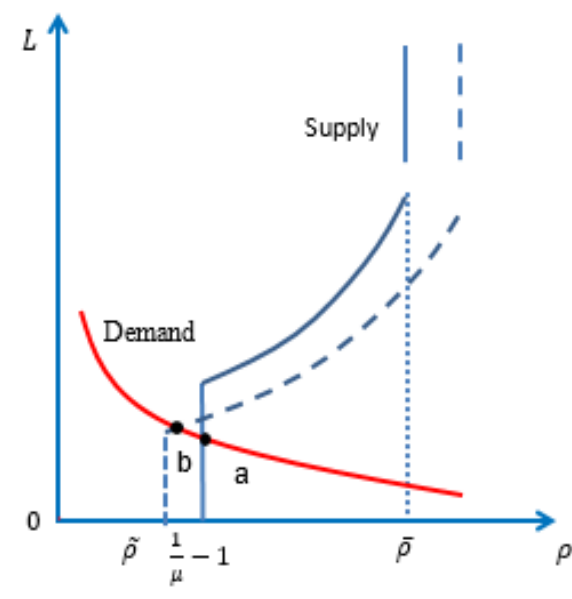

(b) Case 2

Figure 2: Unconstrained in Type 3 meetings and $\chi>0$

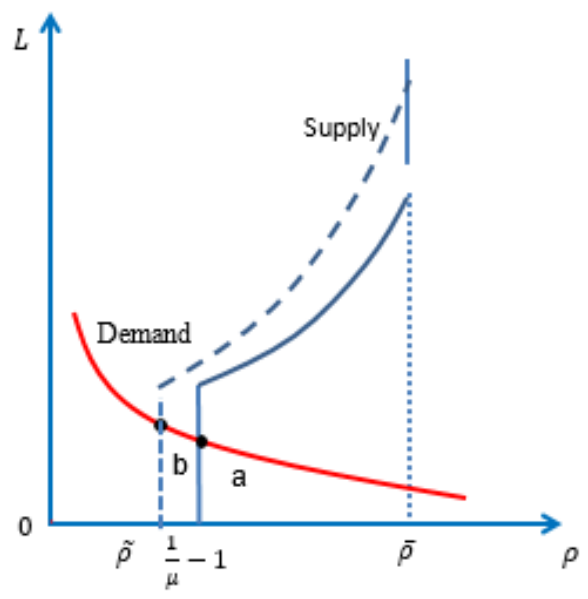

(a) Case 1

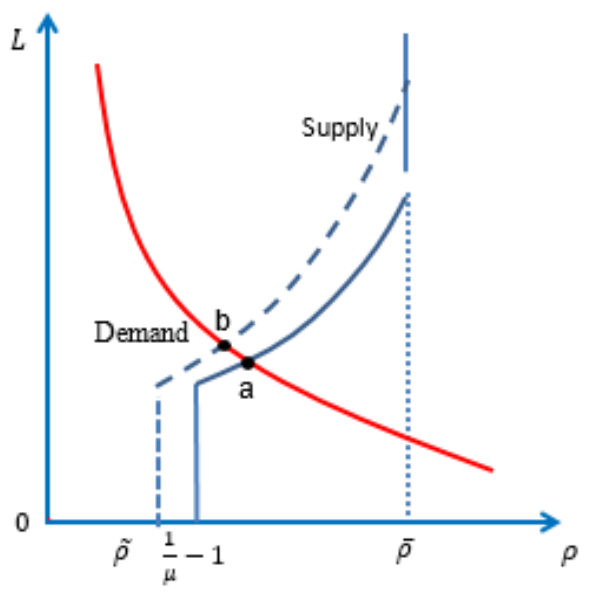

(b) Case 2

Figure 3: $\alpha_{3}>0$ and $\chi=0$ 
interest bearing, in what type of meetings CBDC can be used, and whether banks can hold CBDC and for what purpose (i.e., whether banks can hold it against their reserve requirements or not). We focus on the case where CBDC is interest bearing and designed to be a perfect substitute to bank deposits, i.e. it can be used in type 2 and type 3 meetings. This is likely the case where CBDC will have the most significant impacts on banking. At the end of this section, we briefly discuss the implications of some other types of CBDC.

We consider three cases in this section. First, the bankers are not allowed to hold CBDC. Second, the banks are allowed to hold CBDC but CBDC does not count as reserves. Third, CBDC can be used as reserves. Throughout this section, we only consider the parameters under which the equilibrium lending rate of $\mathrm{CBDC}$ is above $1 / \mu-1$, i.e. we focus on the cases in Figure 1 where $L^{d}$ intersects $L^{s}$ in its strictly increasing region. We then evaluate whether introducing CBDC increase or decrease lending. If instead, the equilibrium lending rate is $1 / \mu-1$ before introducing CBDC, then CBDC only weakly decreases lending. It is worth pointing out that the results in the sections show that one should not judge the usefulness of CBDC based on how much it is used in daily transactions of consumers. Its effect on both deposit and lending rate is a better measure of its usefulness. In the rest of the section, we use $\rho^{*}$ to denote the equilibrium lending rate before the CBDC is introduced. Furthermore, we focus on the case where $\mu<\bar{\mu}$, i.e. bankers are willing to operate without lending opportunities if there is no CBDC.

\subsection{CBDC Not Accessible by Bankers}

Suppose that CBDC grows at a gross rate $\mu_{m}$ and pays a nominal interest $i_{m}$. Both $\mu_{m}$ and $i_{m}$ are policy instruments of the central bank. Let $Z_{E}$ be the real balances 
in CBDC. Then the CM problem of the buyers changes to

$$
\begin{aligned}
W^{B}\left(Z, Z_{E}, D\right)= & Z+D+Z_{E}+T+\max _{x}[U(x)-x] \\
& +\max _{\hat{D}, \hat{Z}_{E}, \hat{Z}}\left\{-\frac{\phi}{\hat{\phi}} \hat{Z}-\frac{\phi_{E}}{\hat{\phi}_{E}} \frac{1}{1+i_{m}} \hat{Z}_{E}-\psi \hat{D}+\beta V\left(\hat{Z}, \hat{Z}_{E}, \hat{D}\right)\right\},
\end{aligned}
$$

where $\phi_{E}$ is the price of CBDC in terms of the numeraire good. It can be different from $\phi$ in equilibrium because the CBDC may pay interests or have different growth rate.

Following the same calculation, one can obtain the steady state demand for all three payment instruments given the deposit rate and policy rates.

$$
\begin{gathered}
\iota \geq \quad \alpha_{1} \lambda(Z)+\alpha_{3} \lambda\left(Z+Z_{E}+D\right), \text { equality iff } Z>0 \\
\frac{\psi}{\beta}-1 \geq \alpha_{2} \lambda\left(D+Z_{E}\right)+\alpha_{3} \lambda\left(Z+Z_{E}+D\right), \text { equality iff } D>0 \\
\frac{\mu_{m}}{\beta\left(1+i_{m}\right)}-1 \geq \alpha_{2} \lambda\left(D+Z_{E}\right)+\alpha_{3} \lambda\left(Z+Z_{E}+D\right), \text { equality iff } Z_{E}>0
\end{gathered}
$$

From the last two equations, we can see that if $\psi>\frac{\mu_{m}}{1+i_{m}}$, the demand for bank deposits is 0 . If $\psi<\frac{\mu_{m}}{1+i_{m}}$, the demand for CBDC is 0 .

As before, (11)-(13) define the demand function of $D$ and $Z_{E}$ as the following

$$
D=\left\{\begin{array}{ll}
\Psi^{-1}(\psi) & \psi<\frac{\mu_{m}}{1+i_{m}} \\
{\left[0, \Psi^{-1}(\psi)\right]} & \psi=\frac{\mu_{m}}{1+i_{m}} \\
0 & \psi>\frac{\mu}{1+i_{m}}
\end{array} \quad \text { and } Z_{E}= \begin{cases}0 & \psi<\frac{\mu_{m}}{1+i_{m}} \\
\Psi^{-1}\left(\frac{\mu}{1+i_{m}}\right)-D & \psi=\frac{\mu_{m}}{1+i_{m}} \\
\Psi^{-1}\left(\frac{\mu}{1+i_{m}}\right) & \psi>\frac{\mu}{1+i_{m}}\end{cases}\right.
$$

where $\Psi$ is the same as the one defined in Section 2 for some $d \in\left[0, \Psi^{-1}\left(\frac{\mu_{m}}{1+i_{m}}\right)\right]$. This defines a new inverse demand function for deposits

$$
\hat{\Psi}(D)=\left\{\begin{array}{ll}
{\left[\frac{\mu_{m}}{1+i_{m}}, \infty\right)} & D=0 \\
\frac{\mu_{m}}{1+i_{m}} & D \in\left[0, \Psi^{-1}\left(\frac{\mu_{m}}{1+i_{m}}\right)\right] \\
\Psi(D) & D \geq \Psi^{-1}\left(\frac{\mu_{m}}{1+i_{m}}\right)
\end{array} .\right.
$$

Figure 4 illustrates $\hat{\Psi}$ and $\Psi$. Introducing CBDC truncates the original inverse demand function for deposits. With CBDC, bankers can no longer drive the deposit rate below $\frac{\mu_{m}}{\beta\left(1+i_{m}\right)}-1$ by restricting the supply of deposits because buyers then will choose to hold CBDC. 


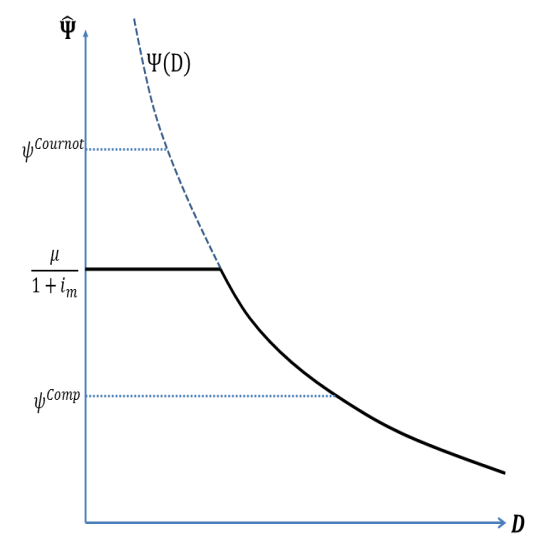

Figure 4: Inverse Demand of Bank Deposits

Following (10) and assuming that $1 / \mu-1 \leq \rho<\bar{\rho}$, we can now write the bank's problem as follows

$$
\max _{\ell_{j}, d_{j}}\left\{\left[(1+\rho)(1-\chi)-c+\frac{\chi}{\mu}\right] \hat{\Psi}\left(d_{-j}+d_{j}\right) d_{j}-d_{j}\right\} .
$$

Denote by $\tilde{D}(\rho)$ the total deposit supply by the banks under $\rho$ and $\hat{\Psi}$. Let $\bar{\psi}(\rho) \equiv$ $\Psi(D(\rho))$ be the price of deposits given by Cournot competition if there is no CBDC and the lending rate is $\rho$. In addition, define $\hat{\psi}(\rho)=\left[(1+\rho)(1-\chi)-c+\frac{\chi}{\mu}\right]^{-1}$, which is the outcome of marginal cost pricing. Notice that $\hat{\psi}(\rho)$ and $\bar{\psi}(\rho)$ are both decreasing in $\rho$ if $D(\rho)$ is strictly increasing. In addition, $\hat{\psi}(\rho)<\bar{\psi}(\rho)$ because bankers just break even at $\hat{\psi}(\rho)$ but earns positive profit at $\bar{\psi}(\rho)$. Then the following lemma holds.

Lemma 2 Suppose Assumption 1 holds. If $\max (1 / \mu, 1+\tilde{\rho})<1+\rho<1+\bar{\rho}$ then

1. If $\frac{\mu_{m}}{1+i_{m}} \in(\bar{\psi}(\rho), \infty), \tilde{D}(\rho)=D(\rho)$;

2. If $\frac{\mu_{m}}{1+i_{m}} \in(\hat{\psi}(\rho), \bar{\psi}(\rho))$, then in the symmetric pure strategy equilibrium $\tilde{D}(\rho)=$ $\Psi^{-1}\left(\frac{\mu_{m}}{1+i_{m}}\right)$;

3. If $\frac{\mu_{m}}{1+i_{m}} \in(0, \hat{\psi}(\rho)), \tilde{D}(\rho)=0$. 
Proof. We only prove 2. The other two are obvious. If $d_{j}<\Psi^{-1}\left(\frac{\mu_{m}}{1+i_{m}}\right)-d_{-j}$, increasing $d_{j}$ does not change the price of the deposit, which is fixed at $\mu_{m} /\left(1+i_{m}\right)$. Then the FOC of bank $j$ is

$$
\xi \frac{\mu_{m}}{1+i_{m}}-1>\xi \hat{\psi}(\rho)-1=0
$$

where $\xi=(1+\rho)(1-\chi)-c+\chi / \mu$. Therefore, bank $j$ can always increase its profit by increasing $d_{j}$.

Now suppose $\tilde{D}(\rho)>\Psi^{-1}\left(\frac{\mu_{m}}{1+i_{m}}\right)$. Because that $\frac{\mu_{m}}{1+i_{m}}<\bar{\psi}(\rho), \tilde{D}(\rho)$ is larger than the Cournot outcome without CBDC. Therefore, by Assumption 1, a banker's marginal profit is

$$
\xi\left[\Psi(\tilde{D}(\rho))+\frac{\tilde{D}(\rho)}{N} \Psi^{\prime}(\tilde{D}(\rho))\right]-1<0 .
$$

This shows that it is profitable for a banker to reduce its supply of deposit. Hence, $\tilde{D}(\rho)>\Psi^{-1}\left(\frac{\mu_{m}}{1+i_{m}}\right)$ cannot happen.

Lemma 2 describes how the amount issued by the banks changes if we introduce an interest bearing $\mathrm{CBDC}$. Interestingly, if the interest rate of CBDC is intermediate, given $\rho$, the deposits created by banks increases and CBDC is not used in transactions. Intuitively, banks restrict their supply to get a higher price if there is no $\mathrm{CBDC}$. If $\mathrm{CBDC}$ is introduced and has an intermediate interest, the interest rate on deposits has to equal the interest on CBDC. Then banks lose the ability to lower the rates on deposit by restricting supply. So they would increase the supply of deposits. As long as the interest rate is not further lowered, banks' profit is increasing in their deposits. Therefore, they supply enough deposits to satisfy all the transaction needs and drive out CBDC from transaction.

This result on deposits quantity translates to the following result on loan supply, 
which is helpful for determining the equilibrium. Define

$$
\begin{aligned}
& \hat{\rho}=\max \left\{\frac{1}{\mu}-1,\left(\frac{1+i_{m}}{\mu_{m}}+c-\frac{\chi}{\mu}\right) \frac{1}{1-\chi}-1\right\}, \\
& \check{\rho}=\bar{\psi}^{-1}\left(\frac{\mu_{m}}{1+i_{m}}\right) \text { if } \Psi\left(N d^{*}(\bar{\rho})\right) \leq \frac{\mu_{m}}{1+i_{m}}<\lim _{\rho \downarrow 1 / \mu-1} \bar{\psi}(\rho) .
\end{aligned}
$$

Here $\hat{\rho}$ is the maximum of two terms. The first term is the return from holding money. If the lending rate is less than the return from money, bankers hold money rather than lending. Therefore, the loan supply is zero. The second term is the marginal cost of lending given that a banker prefers lending rather than holding money and that the deposit rate equals the $\mathrm{CBDC}$ rate. It equals the real rate paid to the depositors plus the deposit handling cost minus the return to the money holding necessary for reserve requirement, all scaled by $1 /(1-\chi)$. The scale is needed because loans are at most $1-\chi$ fraction of total deposits. In other words, the second term is the lowest lending rate at which bankers are willing to operate if it is forced to lend up to the reserve requirement. As a result, if $\rho<\hat{\rho}$, there is no lending, because bankers just hold money or do not operate. If $\rho=\hat{\rho}$, bankers break if it matches the $\mathrm{CBDC}$ rate. While $\check{\rho}$ is the lending rate at which the equilibrium real deposit rate from the Cournot competition without CBDC equals the real CBDC rate. It is only well defined for a range of real CBDC rates. For example, if the $\mathrm{CBDC}$ rates is too high, the deposit rate without $\mathrm{CBDC}$ is always below the CBDC rate for any $\rho$. Similarly, if the real CBDC rates is too low, the deposit rate without $\mathrm{CBDC}$ is always above the $\mathrm{CBDC}$ rate for any $\rho$. By definition, $\check{\rho}$ is larger than $1 / \mu-1$ and at $\check{\rho}$, bankers have positive profit if the deposit rate matches the real rate of $\mathrm{CBDC}$. But $\hat{\rho}$ is $1 / \mu-1$ or at $\hat{\rho}$ bankers break even if the deposit rate matches the real rate of CBDC. Therefore, $\check{\rho}$ is bigger than $\hat{\rho}$ if it is defined. Also notice that both $\check{\rho}$ and $\hat{\rho}$ are increasing in $i_{m}$.

Lemma 3 Suppose Assumption 1 holds. Suppose that the CBDC pays an interest $i_{m}$ such that $\Psi(0)>\frac{\mu_{m}}{1+i_{m}}$ and $\frac{\mu_{m}}{1+i_{m}} \geq \beta$. Then, loan supply with CBDC $\tilde{L}^{s}$ satisfies 
1. If $\frac{\mu_{m}}{1+i_{m}} \geq \lim _{\rho \downarrow 1 / \mu-1} \bar{\psi}(\rho), \tilde{L}^{s}=L^{s}$.

2. If $\Psi\left(N d^{*}(\bar{\rho})\right) \leq \frac{\mu_{m}}{1+i_{m}}<\lim _{\rho \downarrow 1 / \mu-1} \bar{\psi}(\rho)$

$$
\tilde{L}^{s}(\rho)= \begin{cases}0 & \text { if } \rho<\hat{\rho} \\ {\left[0,(1-\chi) \frac{\mu_{m}}{1+i_{m}} \Psi^{-1}\left(\frac{\mu_{m}}{1+i_{m}}\right)\right]} & \text { if } \rho=\hat{\rho} \\ (1-\chi) \frac{\mu_{m}}{1+i_{m}} \Psi^{-1}\left(\frac{\mu_{m}}{1+i_{m}}\right) & \text { if } \rho \in(\hat{\rho}, \check{\rho}) \\ L^{s}(\rho) & \text { if } \rho>\check{\rho}\end{cases}
$$

3. If $\Psi\left(N d^{*}(\bar{\rho})\right)>\frac{\mu_{m}}{1+i_{m}}$,

$$
\tilde{L}^{s}(\rho)=\left\{\begin{array}{ll}
0 & \text { if } \rho<\hat{\rho} \\
{\left[0,(1-\chi) \frac{\mu_{m}}{1+i_{m}} \Psi^{-1}\left(\frac{\mu_{m}}{1+i_{m}}\right)\right]} & \text { if } \rho=\hat{\rho} \\
(1-\chi) \frac{\mu_{m}}{1+i_{m}} \Psi^{-1}\left(\frac{\mu_{m}}{1+i_{m}}\right) & \text { if } \rho \in(\hat{\rho}, \bar{\rho}) \\
\left\{(1-\chi) \frac{\mu_{m}}{1+i_{m}} \Psi^{-1}\left(\frac{\mu_{m}}{1+i_{m}}\right)\right\} \cup\left[\frac{(1-\chi) N \beta y^{*}}{N-1}, \infty\right] & \text { if } \rho=\bar{\rho}
\end{array} .\right.
$$

We omit the proof because it only involves checking the conditions in Lemma 2. This lemma suggests that if the real CBDC rate is too low, it does not affect the loan supply curve. In this case, CBDC is not an attractive alternative to bank deposits and hence no one is willing to hold it in the economy. If $i_{m}$ becomes higher, it starts to reshape the loan supply curve. If $\rho$ is not too high, bankers are then forced to offer deposit at a rate that matches the CBDC rate. But if $\rho$ is sufficiently high, the deposit rate without $\mathrm{CBDC}$ is higher than the real rate of CBDC, then the loan supply curve is not affected. This happens if $\rho>\check{\rho}$ if $i_{m}$ is not too high. However, if $i_{m}$ is sufficiently high, $\tilde{L}^{s}(\rho) \neq L^{s}(\rho)$ for all $\rho>\hat{\rho}$.

To investigate the effects of CBDC, we can plot the loan demand and loan supply curve before and after introducing CBDC. As in previous sections, we focus on the case where $D \Psi(D)$ is increasing. The results are shown in Figure 5. In any of these graphs, the solid red curve is the loan supply curve and the solid blue curve is the loan supply curve without CBDC. They intersect at point a, which is the equilibrium without CBDC. After CBDC is introduced, the loan demand curve is not affected while the loan supply curve is changed to the dashed black line. As 


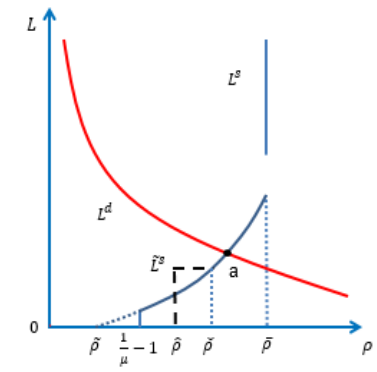

(a) Low $i_{m}$

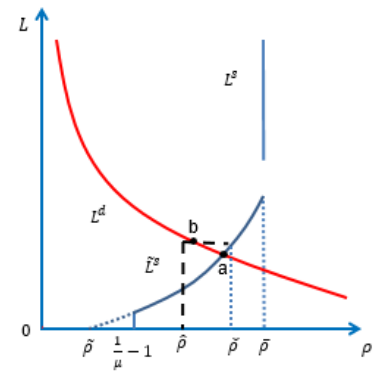

(b) Medium $i_{m}$

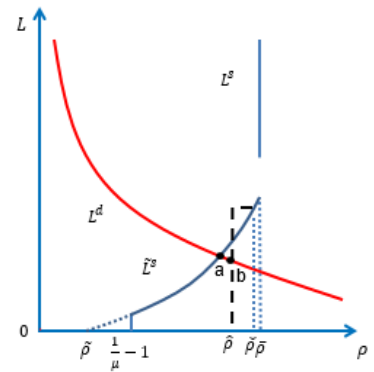

(c) High $i_{m}$

Figure 5: Effects of CBDC

shown by Lemma 3, it has the following properties. If $\rho<\hat{\rho}$, the loan supply is 0 . This is because the loan rate is too low and the rate on deposits cannot fall below $i_{m}$. Then it is not profitable for banks to issue deposits. If $\rho=\hat{\rho}$, the loan rate is sufficiently high to cover the cost of issuing deposits. Hence, banks are indifferent between a range of deposits to offer. But total deposits issued does not go above $\Psi^{-1}\left(\frac{\mu_{m}}{1+i_{m}}\right)$. Otherwise, the deposit rate increases, which reduces the profits of banks. As a result, the total loan can be provided can be any value between 0 and $(1-\chi) \frac{\mu_{m}}{1+i_{m}} \Psi^{-1}\left(\frac{\mu_{m}}{1+i_{m}}\right)$. If $\rho \in(\hat{\rho}, \check{\rho})$, the loan rate is high enough so that issuing more deposit always increases the profit of the banks as long as the deposit rate is not affected. This is because with more deposits, banks can make more loans. Then the loan supply is at $(1-\chi) \frac{\mu_{m}}{1+i_{m}} \Psi^{-1}\left(\frac{\mu_{m}}{1+i_{m}}\right)$. If the dashed black curve joins the solid blue curve at $\check{\rho}$ and if $\rho>\check{\rho}$, these two curves coincide. This is because $\rho$ is sufficiently high and the deposit rate without CBDC is above $i_{m}$. Hence, introducing CBDC does not affect the loan supply and the supply curve coincides with the one without CBDC.

Now if $i_{m}$ is low, as shown in Figure 5(a), the dashed curve joins the solid blue curve before point $a$. Then with CBDC, the equilibrium stays at $a$. As $i_{m}$ increases, both $\hat{\rho}$ and $\check{\rho}$ shifts to the right, and also the horizontal part of the dashed curve increases because $(1-\chi) \frac{\mu_{m}}{1+i_{m}} \Psi^{-1}\left(\frac{\mu_{m}}{1+i_{m}}\right)$ increases with $i_{m}$. If $i_{m}$ is sufficiently high, as in Figure 5(b), the dashed black curve joins the solid blue curve at a point 
to the right of point $a$. Now the equilibrium with CBDC is at point $b$. In this equilibrium, the amount of loans is higher and loan rate is lower. This is because now banks have less incentive to restrict the deposit supply because they have less ability to affect the equilibrium deposit rate. Then they take more deposits, which translates to more loan supply. In this case, further increasing $i_{m}$ increases the loans and decreases the loan rate. Hence, higher interest rate on CBDC increases the intermediation in the economy. If $i_{m}$ further increases, $\hat{\rho}$ increases further to lie to the right of point $a$, as shown in Figure 5(c). Now with the CBDC, the equilibrium has higher lending rate and lower amount of loans. This is the case where introducing CBDC crowds out bank lending and private investment (Keister and Sanches, 2018). The following proposition summarizes these discussions. The effects of CBDC interest rate are depicted schematically in Figure 6 for the case where $c=\chi=0$.

Proposition 4 Suppose bankers cannot hold CBDC. If Assumptions 1-2 hold and $\iota<\bar{\iota}$, there exists at least one monetary equilibrium. Moreover, if $D \Psi(D)$ is increasing, there exists a unique monetary equilibrium and

1. If $i_{m}$ is set such that $\rho^{*} \in(\hat{\rho}, \check{\rho})$, then $C B D C$ increases lending and a higher $i_{m}$ induces more lending.

2. If $i_{m}$ is set such that $\rho^{*}=\hat{\rho}$, then $C B D C$ decreases lending and a higher $i_{m}$ induces less lending.

Proof. In the text above.

This proposition delivers an important message, i.e. introducing CBDC needs not to cause disintermediation by reducing loans and deposits. To the contrary, it may increase lending and deposits by introducing more competition to the banking sector if its rate is appropriately designed. Unlike Andolfatto (2018), our result 


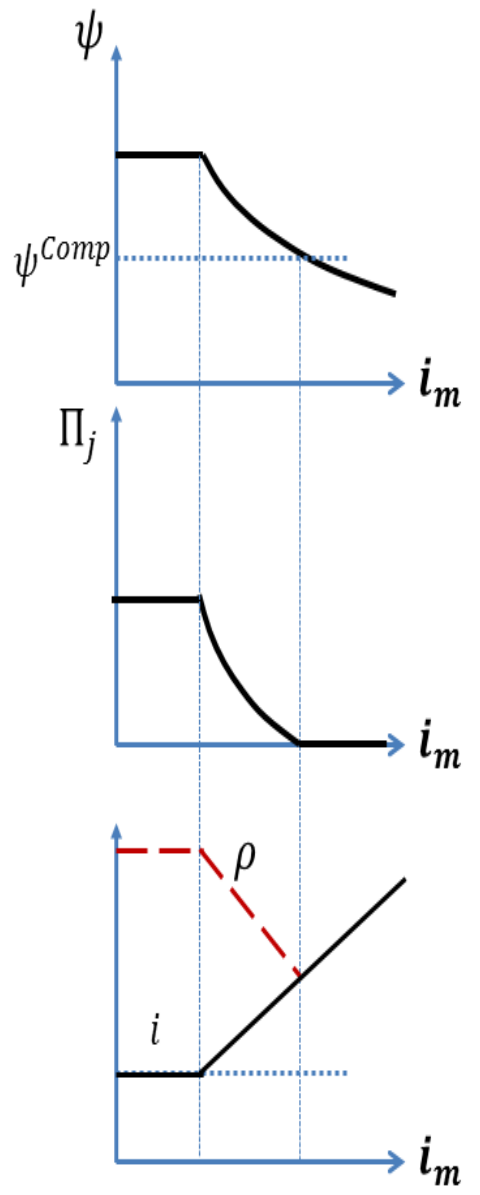

Figure 6: Effects of change in CBDC interest rate with no reserve equirements and $\mathrm{c}=0$. 
does not require that the central bank lends to private banks. It results from the fact that bankers make their deposits more attractive because they have to compete with CBDC. Because their deposits are more attractive, they are able to make more loans in the form of deposits. In addition, they have incentives to do so because their impact on deposit rates is contained by CBDC, i.e. they cannot reduce deposit rate too much by restricting supply of deposit. Also notice that because $\hat{\rho}$ and $\check{\rho}$ are both increasing in $i_{m}$, there exists $\underline{i}_{m}<\bar{i}_{m}$ such that $\rho^{*} \in(\hat{\rho}, \check{\rho})$ iff $i_{m} \in(\underline{i}, \bar{i})$. Therefore, there is a range of $i_{m}$ under which introducing CBDC increases lending. It is also worth noticing that in Figure 5(a), no CBDC is used for transactions. Buyers continue to hold only deposits. However, it has a real effect. Intuitively, existence of CBDC disciplines the off-equilibrium outcome. If the banker's reduces their deposit rates, they know buyers would switch to hold CBDC. In this case, CBDC acts like a potential entrant.

Note the difference between introducing CBDC and introducing another bank. Although in both scenarios the lending and deposit rates both get closer to their perfect competition level, introducing CBDC sets the floor for the deposit rate at any target level that the central bank wants. In contrast, increasing the number of banks affects the deposit rates only indirectly and may not increase the rate to the target level. Moreover, although the central bank/government can affect banks' entry through regulation and taxation in the long run, these tools are unlikely to be useful for influencing the rates in the short run, which is the focus of monetary policy.

If $i_{m}$ increases a little bit more, the $L^{d}$ intersects $\tilde{L}^{s}$ on its vertical region. In this case, CBDC and bank deposits are both used as means of payment. An important implication of this finding is that the usefulness of CBDC should not be judged based on how frequently people use it but rather, on how much it affects the deposit rates. Indeed, CBDC increases lending most if $i_{m}$ is set such that at the equilibrium 
$\rho=\hat{\rho}$. In this case, CBDC is never used as a means of payment.

\subsection{CBDC Accessible by Bankers}

Now suppose bankers have access to CBDC but CBDC does not serve as reserve. They now can choose whether to lend to backs, hold cash reserves or hold CBDC. If CBDC gives higher rates than lending, they choose to hold CBDC. Under this scenario, CBDC has the most negative impact on bank lending given CBDC is designed as a perfect substitute to bank deposits. First, bankers cannot hold CBDC as reserves and hence interests on CBDC does not reduce the cost of holding reserves. Second, because CBDC pays interest, the bankers may want to choose holding CBDC instead of making loans. We are going to show that even under this scenario, introducing $\mathrm{CBDC}$ can help lending if the interest rate on CBDC is set properly.

Their problem changes to

$$
\begin{gathered}
\max _{z_{j}^{E}, z_{j}, \ell_{j}, d_{j}}\left\{(1+\rho) \ell_{j}+\frac{z_{j}}{\mu}+\frac{\left(1+i^{m}\right) z_{j}^{E}}{\mu_{m}}-\left[d_{j}+\hat{\Psi}\left(d_{-j}+d_{j}\right) d_{j} c\right]\right\} \\
\text { st } \quad \ell_{j}+z_{j}+z_{j}^{E}=\hat{\Psi}\left(d_{-j}+d_{j}\right) d_{j} . \\
z_{j} \geq \chi \hat{\Psi}\left(d_{-j}+d_{j}\right) d_{j} .
\end{gathered}
$$

If $1 / \mu>\left(1+i^{m}\right) / \mu_{m}$, the bankers continue to hold only money if the lending opportunity is not good because fiat money has higher return compared to CBDC. If $1 / \mu \leq\left(1+i^{m}\right) / \mu_{m}$, then the bankers would instead hold CBDC because it has higher return. In both cases, the bankers operate if $\rho$ is sufficiently high so they at least break even. Recall that without CBDC, the break-even $\rho=\hat{\rho}$. Now with CBDC, if $1 / \mu>\left(1+i^{m}\right) / \mu_{m}$, the break-even point remains $\hat{\rho}$ because bankers never hold CBDC. If $1 / \mu \leq\left(1+i^{m}\right) / \mu_{m}$, then $\hat{\rho}>\left(1+i^{m}\right) / \mu_{m}-1$. Intuitively, bankers can never break even if $\hat{\rho} \leq\left(1+i^{m}\right) / \mu_{m}-1$ because bankers need to pay $\left(1+i^{m}\right) / \mu_{m}-1$ to depositors and incurs cost of holding reserves and handling deposits given $\chi>0$ or $c>0$. If $\chi=0$ and $c=0, \hat{\rho}=\left(1+i^{m}\right) / \mu_{m}-1$. The above 
analysis means that without loss of generality, we can assume that they do not hold CBDC as a saving instrument.

Proposition 5 Suppose bankers can hold $C B D C$ as a saving instrument but not as reserve. If Assumptions 1-2 hold and $\iota<\bar{\iota}$, there exists at least one monetary equilibrium. Moreover, if $D \Psi(D)$ is increasing, there exists a unique monetary equilibrium. $C B D C$ increases lending if $i_{m}$ is set such that $\rho^{*} \in(\hat{\rho}, \check{\rho})$. Further more, higher $i_{m}$ induces more lending if the equilibrium lending rate $\rho_{E}^{*} \in(\hat{\rho}, \check{\rho})$.

Interestingly, not only Proposition 5 holds, the equilibria coincide with the case where bankers cannot hold CBDC. This is because if bankers operates, $\hat{\rho}$ must be above the $\mathrm{CBDC}$ rate and as a result, bankers do not hold CBDC in equilibrium.

\subsection{CBDC as Reserves}

Lastly, we consider the case where bankers can hold CBDC as Reserves. Then the banker's problem becomes

$$
\begin{gathered}
\max _{z_{j}^{E}, z_{j}, \ell_{j}, d_{j}}\left\{(1+\rho) \ell_{j}+\frac{z_{j}}{\mu}+\frac{\left(1+i^{m}\right) z_{j}^{E}}{\mu_{m}}-\left[d_{j}+\hat{\Psi}\left(d_{-j}+d_{j}\right) d_{j} c\right]\right\} \\
\text { st } \quad \ell_{j}+z_{j}+z_{j}^{E}=\hat{\Psi}\left(d_{-j}+d_{j}\right) d_{j} . \\
z_{j}^{E}+z_{j} \geq \chi \hat{\Psi}\left(d_{-j}+d_{j}\right) d_{j} .
\end{gathered}
$$

Then if $\max \left\{1 / \mu,\left(1+i^{m}\right) / \mu^{m}\right\}-1<\rho<\bar{\rho}$. The banker's problem changes to

$$
\max _{\ell_{j}, d_{j}}\left\{\left[(1+\rho)(1-\chi)-c+\chi \max \left(\frac{1}{\mu}, \frac{1+i^{m}}{\mu^{m}}\right)\right] \hat{\Psi}\left(d_{-j}+d_{j}\right) d_{j}-d_{j}\right\} \text {. }
$$

To solve for the equilibrium, we first solve for the equilibrium where the households cannot hold CBDC. In this case, all the analysis in Section 3 goes through if we 
replace $1 / \mu$ by $\max \left\{1 / \mu,\left(1+i^{m}\right) / \mu^{m}\right\}$ everywhere. More specifically, let

$$
\begin{aligned}
\tilde{\rho}_{R} & =\left[\frac{1}{\Psi(0)}+c-\max \left(\frac{1}{\mu}, \frac{1+i_{m}}{\mu_{m}}\right)\right](1-\chi)^{-1}+\max \left(\frac{1}{\mu}, \frac{1+i^{m}}{\mu^{m}}\right)-1, \\
\bar{\rho}_{R} & =\frac{c+1 / \beta+\chi\left[1-\max \left(\frac{1}{\mu}, \frac{1+i_{m}}{\mu_{m}}\right)\right]}{1-\chi}, \\
\xi_{R} & =\max \left\{\left[1+\rho-\max \left(\frac{1}{\mu}, \frac{1+i_{m}}{\mu_{m}}\right)\right](1-\chi), 0\right\}+\max \left(\frac{1}{\mu}, \frac{1+i^{m}}{\mu^{m}}\right)-c, \\
\xi_{R}^{-1} & =\Psi^{\prime}\left(N d_{R}^{*}(\rho)\right) d_{R}^{*}(\rho)+\Psi\left(N d_{R}^{*}(\rho)\right) .
\end{aligned}
$$

Now $\tilde{\rho}_{R}, \bar{\rho}_{R}$ and $\xi_{R}$ are the counterpart of $\tilde{\rho}, \bar{\rho}$ and $\xi$. The difference is that now these rates takes into account that $\mathrm{CBDC}$ serves as reserve and pays interest. Then we can define

$$
D_{R}(\rho)= \begin{cases}0 & \text { if } \mu>\bar{\mu} \text { and } \rho<\tilde{\rho}_{R} \\ N d_{R}^{*}(\rho) & \text { if } \rho<\bar{\rho}_{R} \text { and } \beta<\mu<\bar{\mu} \\ {\left[\frac{N}{N-1} y^{*}, \infty\right] \cup\left\{N d_{R}^{*}(\rho)\right\}} & \text { if } \rho>\tilde{\rho}_{R} \text { and } \mu>\bar{\mu} \\ \infty & \text { if } \rho>\bar{\rho}_{R}\end{cases}
$$

to be the new deposit function. Notice that now $D_{R}(\rho)$ is increasing in $i^{m}$ under Assumption 1 because higher $i^{m}$ increases $\xi_{R}$. Then we can obtain the loan supply curve

$$
\tilde{L}_{R}^{s}(\rho)=\left\{\begin{array}{ll}
0 & \text { if } \rho<\hat{\rho}_{R} \\
{\left[0,(1-\chi) \frac{\mu_{m}}{1+i_{m}} \Psi^{-1}\left(\frac{\mu_{m}}{1+i_{m}}\right)\right]} & \text { if } \rho=\hat{\rho}_{R} \\
(1-\chi) \frac{\mu_{m}}{1+i_{m}} \Psi^{-1}\left(\frac{\mu_{m}}{1+i_{m}}\right) & \text { if } \rho \in\left(\hat{\rho}_{R}, \check{\rho}_{R}\right) \\
L_{R}^{s}(\rho) & \text { if } \rho>\check{\rho}_{R}
\end{array} .\right.
$$

where $L_{R}^{s}(\rho)$ is the loan supply if the households cannot hold CBDC

$$
L_{R}^{s}(\rho)= \begin{cases}0 & \text { if } \rho<\max \left(\frac{1}{\mu}, \frac{1+i^{m}}{\mu^{m}}\right)-1 \\ {\left[0,(1-\chi) D_{R}(\rho) \Psi\left(D_{R}(\rho)\right)\right]} & \text { if } \rho=\max \left(\frac{1}{\mu}, \frac{1+i^{m}}{\mu^{m}}\right)-1 \\ (1-\chi) D_{R}(\rho) \Psi\left(D_{R}(\rho)\right) & \text { if } \rho \in\left(\max \left(\frac{1}{\mu}, \frac{1+i^{m}}{\mu^{m}}\right)-1, \bar{\rho}_{R}\right) \\ \left\{(1-\chi) N d_{R}^{*}(\rho) \Psi\left(N d_{R}^{*}(\rho)\right)\right\} \cup\left[\frac{(1-\chi) N \beta y^{*}}{N-1}, \infty\right] & \text { if } \rho=\bar{\rho}_{R} \\ \infty & \text { if } \rho>\bar{\rho}_{R}\end{cases}
$$

$\check{\rho}_{R}$ solves $\Psi\left(D_{R}(\rho)\right)=\mu_{m} /\left(1+i_{m}\right)$ and

$$
\hat{\rho}_{R}=\max \left\{\frac{1}{\mu}, \frac{\frac{1+i_{m}}{\mu_{m}}-\chi \max \left(\frac{1}{\mu}, \frac{1+i_{m}}{\mu_{m}}\right)+c}{1-\chi}\right\}-1 .
$$




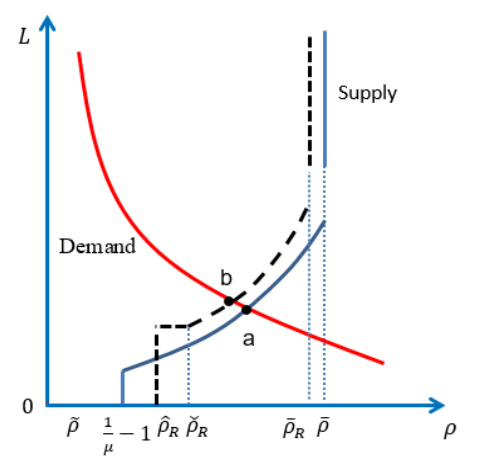

(a) Low $i_{m}$

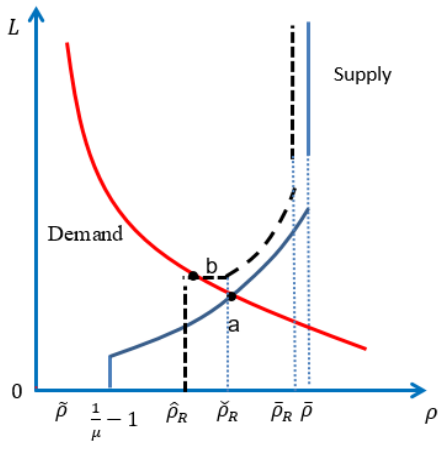

(b) Medium $i_{m}$

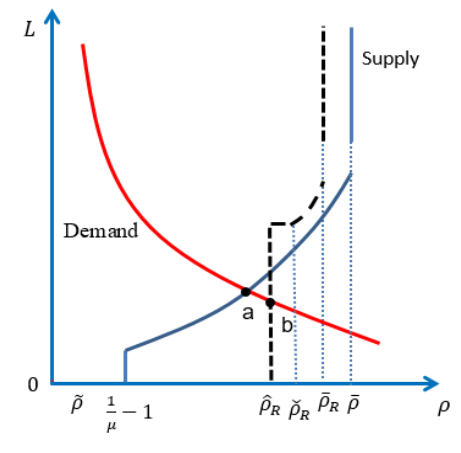

(c) HIgh $i_{m}$

Figure 7: CBDC as Reserve

Notice that under Assumption 1, $\tilde{L}_{R}^{s}(\rho) \geq L_{R}^{s}(\rho)$ for all $\rho>\hat{\rho}_{R}$. This is because bankers can earn interest on their reserves by holding CBDC. Also notice that $1 / \mu \geq$ $\left(1+i_{m}\right) / \mu_{m}, \hat{\rho}_{R}=\hat{\rho}$. Otherwise, $\hat{\rho}_{R}<\hat{\rho}$, which suggests that bankers are willing to lend at a lower $\rho$.

Proposition 6 Suppose bankers can hold $C B D C$ as reserve. If Assumptions 1-2 hold and $\iota<\bar{\iota}$, there exists at least one monetary equilibrium. Moreover, if $D \Psi(D)$ is increasing, there exists a unique monetary equilibrium. CBDC increases lending if $i_{m}$ is set such that $\rho^{*}>\hat{\rho}_{R}$ and $i_{m}>\mu_{m} / \mu-1$. Furthermore, higher $i_{m}$ induces more lending if the equilibrium lending rate $\rho_{R}^{*}>\hat{\rho}_{R}$.

Figure 7 illustrates the result. The solid blue lines are the loan supply before introducing $\mathrm{CBDC}$ and the dashed black lines are that after introducing CBDC. Similar as in the previous two subsections, the loan supply curve is fat if $\rho \in\left(\hat{\rho}_{R}, \check{\rho}_{R}\right)$. Unlike in previous two subsections, CBDC increases loan supply for all $\rho>\hat{\rho}_{R}$. In particular, the $\tilde{L}_{R}^{s}(\rho)$ does not overlap with $L^{s}(\rho)$ for $\rho$ sufficiently high. This is because interest on reserves lowers the cost of lending, which would increase lending even if there is no competition effect.

Figure $7(\mathrm{a})$ shows the case where CBDC rate is larger than $\mu_{m} / \mu-1$ but still lower than the deposit rate in the equilibrium without CBDC. The loan demand 
curve intersects the loan supply curve with CBDC in its increasing region. In this case, buyers strictly prefer bank deposit over CBDC. As a result, CBDC does not introduce additional competition. However, the equilibrium with CBDC (point $b$ ) still features higher bank lending compared to the equilibrium without (point $a$ ). This additional lending is induced the fact that CBDC has higher return than money and hence reduces the cost of holding reserves for lending.

Figure 7(b) shows the case where CBDC rate is higher than the deposit rate when there is no CBDC but still not to high so that $\rho^{*}>\hat{\rho}_{R}$. Now the red curve intersects the dashed black curve in its flat region. CBDC induces more lending through two effects. First, it reduces the cost of holding reserves. Second, it introduces more competition to the deposit market. In Figure 7(a) and Figure 7(b), $\rho_{R}^{*}>\hat{\rho}_{R}$, higher CBDC rate introduces lending. Moreover, $\mathrm{CBDC}$ is not used in the equilibrium,

If the CBDC rate is sufficiently, then $\rho^{*}<\hat{\rho}_{R}$. The equilibrium is shown in Figure $7(\mathrm{c})$. The red curve intersects the black dashed line on its vertical region. Now CBDC is used by households for payment. And the equilibrium lending rate equals $\hat{\rho}_{R}$. In this case, CBDC is too attractive, bankers then hold CBDC instead of lending to entrepreneurs. As a result, lending shrinks. In addition, higher $i_{m}$ increases $\hat{\rho}_{R}$ and decreases bank lending.

Notice that all the analysis above assumes that except CBDC, bankers can only hold money as reserves. If bankers can hold other type of central bank reserves that pays interest, all the above analysis stays valid if we replace $1 / \mu$ everywhere by $\left(1+i_{r}\right) / \mu$ where $i_{r}$ is the interest rate on central bank reserves. In other words, the above analysis can be viewed as a special case where $i_{r}=0$.

\subsection{Implications of Other Designs of CBDC}

Suppose CBDC is still interest bearing, but it is a perfect substitute for cash, i.e., it can be used in type 1 and type 3 meetings. Again, we focus on the cases in Figure 1 where $L^{d}$ intersects $L^{s}$ in its strictly increasing region. If the nominal interest rate 
that CBDC pays is above zero, then it dominates cash for households, so households do not hold cash.

If CBDC serves as reserves, a higher CBDC rate can potentially have two effects: a cost reduction effect and a substitution effect. The cost reduction effect is present because a higher CBDC rate reduces bankers' cost of holding reserves. This effect increases lending. The substitution effect can be present because a higher CBDC rate can reduce the demand for deposits by making $\mathrm{CBDC}$ more attractive. This reduces bank deposits and lending. The cost reduction effect is always present, while the substitution effect is active if and only if CBDC and deposits are substitutes, which happen if and only if households are constrained in type 3 meetings. The net effect of a higher CBDC rate on lending depends on which of the two effects dominates and hence is in general ambiguous. But if households are not constrained in type 3 meetings, a higher CBDC rate increases lending.

If CBDC does not serve as reserves, only the substitution effect can be present. Then a higher CBDC rate weakly reduces lending.

\section{Quantitative Analysis}

In the previous section, we establish theoretically that an interest-bearing CBDC can increase bank lending if the interest rate is in certain range. However, it remains an empirical question how large the range is. This is crucial for policy decisions. To answer this question, we calibrate our model to the US data and then conduct counterfactual analysis to evaluate (1) how large the relevant range of interest is;

(2) how much additional lending can be created by CBDC; (3) what is the effect on output and welfare.

We consider an annual model. First, we parametrize the model such that $U(x)=$ $B \log x, u(y)=y^{1-\sigma} /(1-\sigma)$ and $f(k)=A k^{\eta}$. We first set $\beta=0.96$ and $\mu=1.02$. The cost of handling deposit $c$ is chosen to be 0.03 , which is close to the per deposit 
cost of several commercial banks (total expenses divided by total deposits). The reserve requirement ratio $\chi$ is set to be 0.1 to match the regulation in the US. We also set $\eta=0.66$ to match the elasticity of commercial loans with respect to the prime rate. Then the remaining unknowns are $\left(A, B, N, \alpha_{1}, \alpha_{2}, \alpha_{3}, \sigma\right)$. To proceed, we first set the sum of all $\alpha$ 's to be 0.5 because it is difficult to separately identify the total DM trading probability and $\sigma$ (Lagos and Wright 2005). Second, according to the Survey of Consumer Payment Choice, the fraction of online transactions is around $25.37 \%$ of total transactions. ${ }^{7}$ Therefore, we set $\alpha_{2}=0.1268$. Lastly, we choose $\left(A, B, N, \alpha_{1}, \sigma\right)$ to jointly match the money demand curve and the ratio of cash holding to checking account balances. The latter is calculated from the Survey of Consumer Payment Choice in 2016. Table 1 summarizes all the results. In particular, we obtain that around $4.4 \%$ of transactions do not accept cash. Figure 8 shows the money demand curve from the model and the data. In the data, the money demand becomes close to constant if the interest rate is sufficiently high. Our model is able to capture this feature because we have three types of meetings. Intuitively, when inflation is sufficiently high, households become constrained in type 3 meetings. As a result, the money demand becomes less elastic. For more details on data and calibration, see Appendix C.

\subsection{Effects of CBDC Lending}

Now we consider introducing a CBDC that is a perfect substitute. We consider both the case where CBDC does not serve as reserve and the case where CBDC serves as reserve. The growth rate of $\mathrm{CBDC}$ is set to be the same as the fiat money. We then focus on how changes in CBDC rate affect the real economy as well as deposit and lending rate. In particular, we are interested in whether CBDC increase lending

\footnotetext{
${ }^{7}$ This is calculated using data from 2016. See Greene and J. Stavins (2018). We sum up the total number of online transactions, online bill payments and automatic bill payments. Then we divide this number by the total number of transactions. We have also experimented with data from 2015 or 2017. Results are very similar.
} 


\begin{tabular}{llll}
\hline \hline Parameters & Notation & Value & Notes \\
\hline Calibrated externally & & & \\
Discount factor & $\beta$ & 0.96 & Standard in literature \\
Curvature of production & $\eta$ & 0.66 & Elasticity of commericial loans \\
Money growth rate & $\mu$ & 1.02 & $2 \%$ inflation \\
Prob of Type 2 meeting & $\alpha_{2}$ & 0.1268 & Frac. of online purchase (SCPC) \\
Cost of handling deposits & $c$ & 0.03 & Banks expenses/deposits 3\% \\
Reserve requirement & $\chi$ & 0.1 & US regulation \\
& & & \\
Calibrated internally & & & \\
Prob of Type 1 meeting & $\alpha_{1}$ & 0.0221 & Cash/Checking Ratio \\
Prob of Type 3 meeting & $\alpha_{3}$ & 0.3510 & \\
Coeff. on CM consumption & $B$ & 1.2011 & Money demand curve \\
Curv. of DM consumption & $\sigma$ & 0.1605 & Money demand curve \\
TFP & $A$ & 1.1646 & Deposit rate 0.05\% \\
Number of Banks & $N$ & 4 & NIM 2.98\% (Dempsey 2018) \\
\hline \hline
\end{tabular}

Table 1: Calibration Results

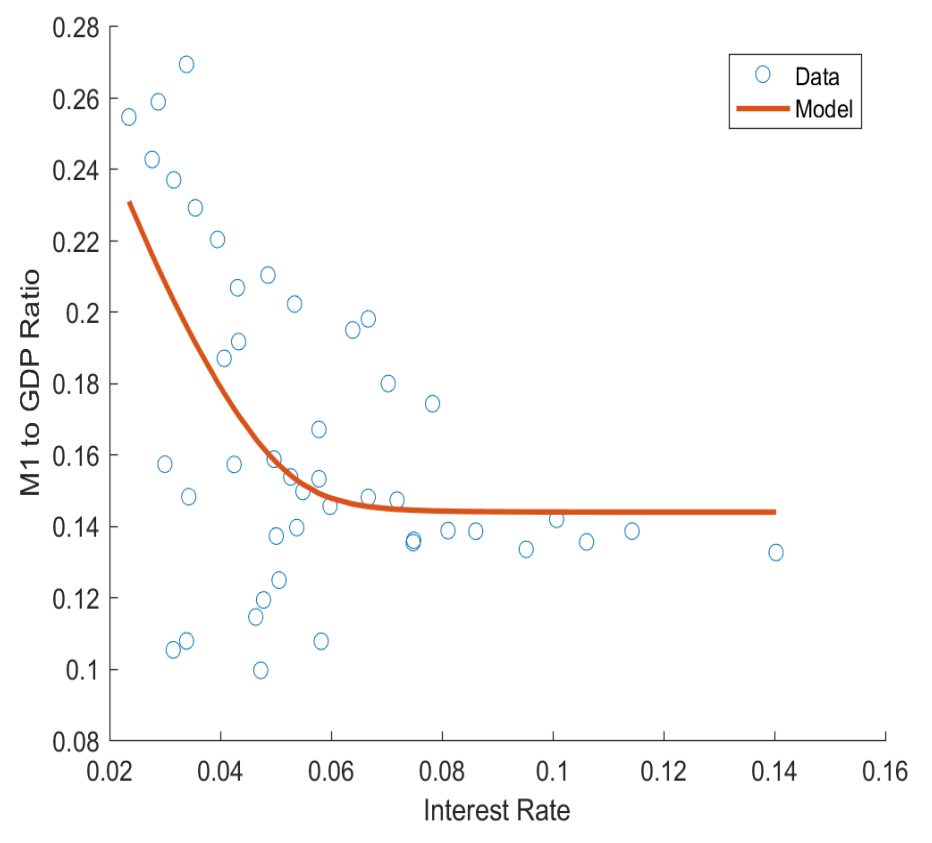

Figure 8: M1 to GDP Ratio Versus Interest Rate 
and output.

Figure 9 shows the result. The first column are real variables divided by corresponding equilibrium values without $\mathrm{CBDC}$, as the $\mathrm{CBDC}$ rate changes. The second column are the changes in deposit and loan rates; and their difference, i.e., the spread. The blue curve is constructed assuming that CBDC does not serve as reserve and the red curve is under the scenario where CBDC serves as reserve. Notice all the rates are nominal rates and are in percentages.

Let us first focus on the total amount of loans, which is shown in the second graph in the first column. If $i_{m}$ is lower than 0 , the real rate of CBDC is below that of fiat money. Therefore, it is not used and the economy behave as if there is no CBDC. In this region, the blue and the red curve overlaps. Although it is not clear in the graph, the red curve started to increase as $i_{m}$ increases to 0 while the blue curve stays put before $i_{m}$ goes above some positive value. In this region, the deposit rate without $\mathrm{CBDC}$ is still above the $\mathrm{CBDC}$ rate. Therefore, $\mathrm{CBDC}$ is not a direct competitor to the deposit. If it does not serve as reserve, it does not change the equilibrium. But if CBDC serves as reserve, interest on CBDC reduces lending cost and increases lending. This is because by the reserve requirement regulation, bankers have to hold reserves for deposits. Without CBDC, holding the only reserve, which is fiat money, is costly because there is inflation. CBDC reduces this cost because it pays positive interest. But this effect is very small and therefore not obvious in the graph.

If $i_{m}$ further increases, CBDC becomes an attractive competitive to the bank deposits, which forces the bankers to increases their deposit rates, which increases the demand for deposits and bank lending. Notice in this region, the blue curve again overlaps with the red curve. This is consistent with our theoretic results in the previous sections. In this region, the equilibrium $\rho$ is in $(\hat{\rho}, \check{\rho})$ when $\mathrm{CBDC}$ does not serve as reserve. As a result, CBDC serving as reserve does not change the 
equilibrium.

However, if $i_{m}$ is sufficiently high, the both curves start to decrease. In this case, bankers act like in a perfectly competitive deposit market and their profit is driven to 0 . To compensate the higher deposit rate, they have to charge higher lending rate, which reduces lending. In this region, it increases lending if CBDC serve as reserve. Therefore, the red curve is always above the blue curve. This happens because CBDC pays positive interest and reduces the lending cost for bankers.

If we set $i_{m}$ to maximize lending, we can increase lending by $5.82 \%$ if the CBDC does not serve as reserve and by $5.97 \%$ if the CBDC serves as reserve. Lending increases in $i_{m}$ if $i_{m}$ is below around $0.44 \%$. And introducing CBDC increases lending if its rate is between $0.05 \%$ and $2.25 \%$ if it does not serve as reserve, and if its rate is between $0 \%$ and $2.50 \%$.

To summarize, the region of $i_{m}$ in which CBDC increases bank lending is more than $2 \%$. As a result, it is less a concern that introducing CBDC would reduce lending. In addition, an appropriate $i_{m}$ can increase bank lending by around $6.0 \%$, which is substantial.

\subsection{Effects on Total Output}

Now we move to total output which is shown in the third graph in the first column. The pattern is similar to the loan: at $i_{m}$ increases, total output first increases and then decreases. Quantitatively, there are two differences. First, the increase in output is much smaller. The highest increase is $0.96 \%$ if CBDC does not serve as reserve and $0.99 \%$ if CBDC serves as reserve, both are achieved at $i_{m}=0.44 \%$. Second, introducing CBDC increases total output iff $i_{m} \in(0.05 \%, 1.66 \%)$ when it does not serve as reserve and iff $i_{m} \in(0,1.81 \%)$ when it serves as reserve. These are

much smaller compared to the regions where lending increases but still more than $1.5 \%$.

The effects on total output is smaller compared to the effect on lending because 

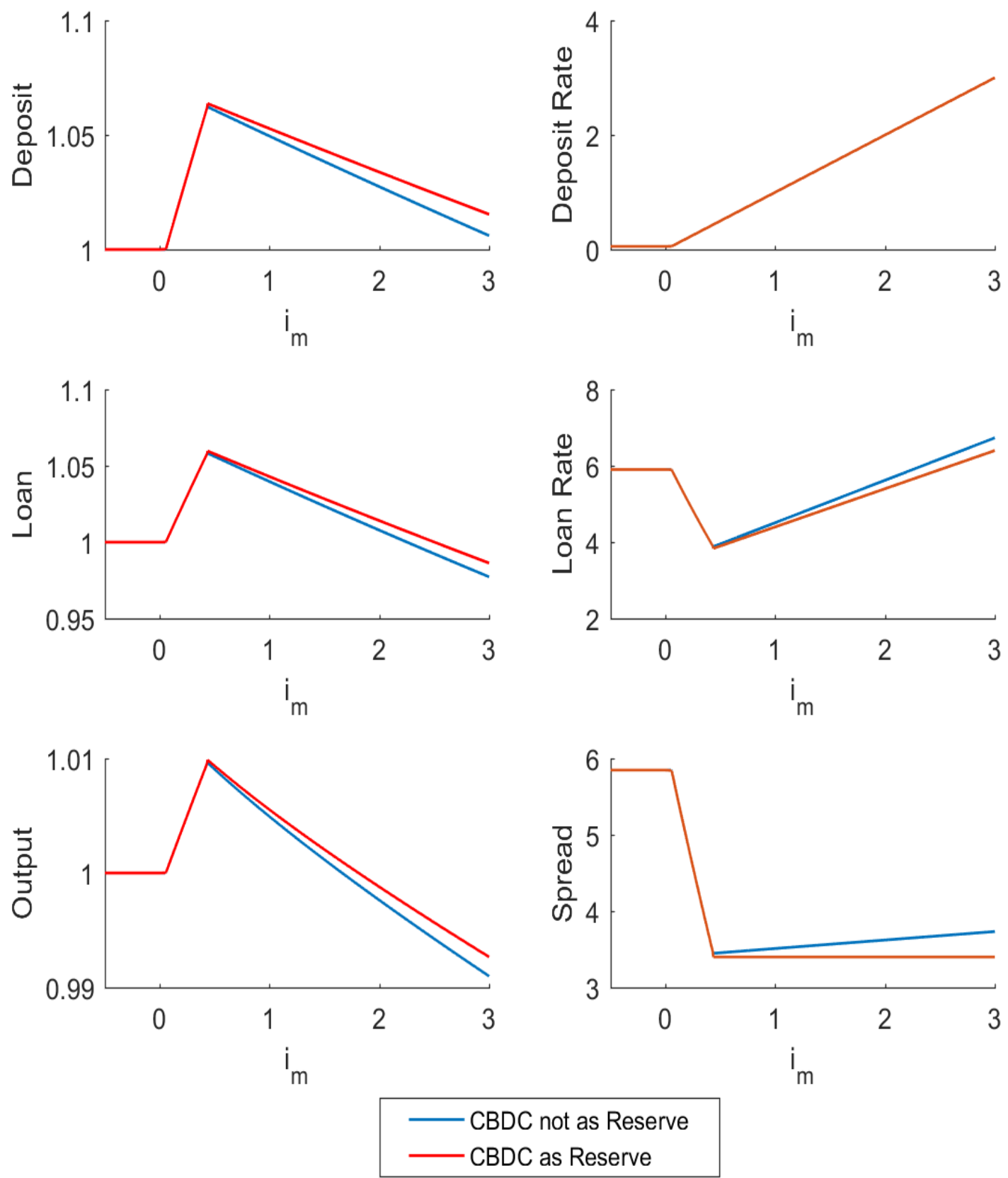

Figure 9: Effects of CBDC Rate 
there is an off-setting effect of CBDC. If CBDC becomes more valuable, households substitute out of money and hold more CBDC. As a result, they choose lower money holdings and hence can consume less in type 1 meetings, which reduces total output. It turns out under the calibrated parameters, this off-setting effect is large and as a result total output falls.

\subsection{Effects on Interest Rates}

The second column of Figure 9 shows how deposits, lending rates and spread change with the CBDC rate. All these rates are nominal.

The deposit rate is shown in the first panel in the second column. It is constant if $i_{m}$ is low and then it coincides with the $45^{\circ}$-line. This reflects that the CBDC rate serves as a floor of the deposit rate rate. It is also worth noting that if $i_{m}$ is positive but small, the deposit rate increases if CBDC can be used as reserve. But the effect is too small to discern in the graph.

The loan rate has the inverse pattern of the loan rate, as shown in the second panel. If $i_{m}$ is set appropriately, the loan rate reduces to less than $4 \%$ from around $6 \%$ when there is no CBDC. But if $i_{m}$ is too high, the loan rates can be higher compared to the no CBDC equilibrium.

The spreads, which is the difference between the nominal lending rate and the nominal deposit rate, are shown in the third panel in the second column. The spread is increasing in bankers' market power. CBDC reduces spreads by introducing more competition into the deposit market. If $i_{m}$ is sufficiently high, bankers act as if the market is perfectly competitive. Then the lending rate equals the marginal cost of lending, which is the cost of maintaining deposits and holding reserves. Interestingly, even if $i_{m}$ is sufficiently high, the spread increases if CBDC does not serve as reserve. However, this does not mean that bankers have higher market power as $i_{m}$ increases. Intuitively, under perfect competition, bankers need the spread to be high enough to compensate the difference between the deposits rate, which is equal to $i_{m}$, and rate 
on reserve. If $\mathrm{CBDC}$ does not serve as reserve, this difference increases as the rate on reserve keeps constant at 0 . Bankers need to have a higher spread. However, if CBDC serve as a reserve, this difference is constant and therefore, the spread keeps constant as shown by the red curve.

\subsection{Effects on Welfare}

We end this section with a discussion on welfare. Figure 10 shows changes in welfare for buyers, entrepreneurs and bankers. We do not show the effect on sellers because their welfare are not affected by CBDC. ${ }^{8}$ Welfare is measured as the percentage change in the equilibrium consumption without CBDC that makes an agent indifferent between no $\mathrm{CBDC}$ and $\mathrm{CBDC}$ with interest rate $i_{m}$. If it is positive, $\mathrm{CBDC}$ increases the welfare of the agent. Otherwise, CBDC reduces the welfare. All the $\mathrm{y}$-axes are in percentages.

CBDC can have a positive effect on buyers which increases in $i_{m}$ on the range in concern. Without hurting lending, buyers' surplus can be raised by around $1 \%$. Entrepreneurs benefit most from CBDC. Their maximum welfare gain is about $4 \%$. CBDC improves their welfare as long as $i_{m}$ does not exceed $2.25 \%$ if CBDC does not serve as reserve and does not exceed $2.50 \%$ if it serves as reserve. Intuitively, entrepreneurs benefit directly from lower lending rate. The buyers benefit from higher deposit rate but suffer from less valuable money. Therefore, the welfare gain for the buyers are much smaller.

Bankers loses because CBDC introduces more competition to the deposit market. If $i_{m}$ is sufficiently high, bankers behave as if the market is perfectly competitive. Their profit and hence consumption is reduces to 0 , which is a $100 \%$ reduction compared to the equilibrium without CBDC.

\footnotetext{
${ }^{8}$ This is because we assume that buyers make take-it-or-leave-it offer in the DM. Therefore, sellers do not get surplus from the DM transactions.
} 


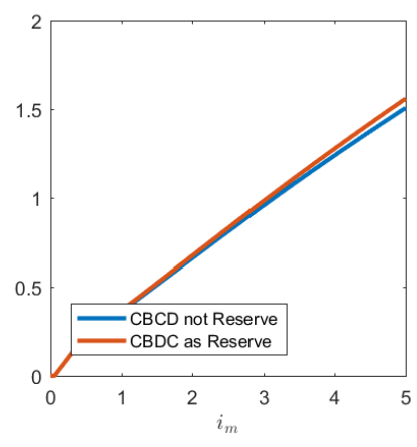

(a) Buyers

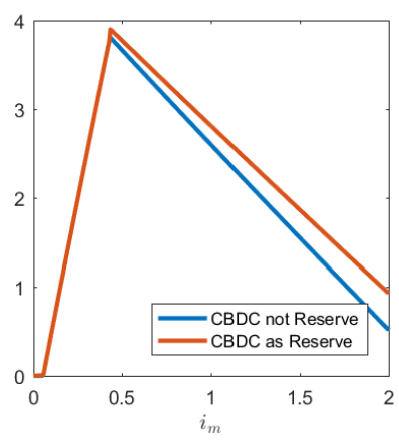

(b) Entrepreneurs

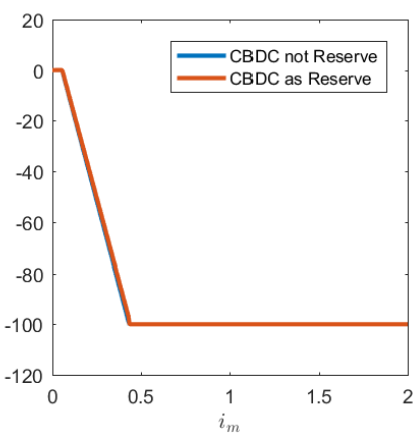

(c) Bankers

Figure 10: Welfare Change for Each Type

\subsection{Robustness}

The quantitative results depend crucially on the value of $\alpha_{1}, \alpha_{2}$ and $\alpha_{3}$. In this subsection, we consider an alternative method to calibrate these free parameters and assess the robustness of our results. For this calibration, we rely on the Diary of Consumer Payment Choice data from the Federal Reserve Bank of Atlanta website. In the diary, respondents are asked whether cash and credit/debit card would have been accepted in each transactions. From 2016 data, people report that around 15\% transactions do not accept credit/debit card and around $2 \%$ of transactions do not accept cash. Assuming that every transaction at least accepts cash or cards, the above number implies that $\alpha_{1}=0.075, \alpha_{2}=0.01$ and $\alpha_{3}=0.415$. Notice that we maintain the assumption that the sum of $\alpha$ s equals $0.5 .^{9}$ The parameters are shown in Table 2. Notice that this result is very different compared to the benchmark calibration. In particular, $15 \%$ of transactions accept only cash compared to $4.4 \%$ in the benchmark case. And $2 \%$ of transactions accept only deposits compared to $25.37 \%$ in the benchmark case. Therefore, the market power of banks is much lower in this case because deposits are not as useful. Given the choices of $\alpha$ s are very different from the benchmark, it is not surprising other parameters are very different.

\footnotetext{
${ }^{9}$ See "Guide to the 2016 Diary of Consumer Payment Choice" available at the website of the Federal Reserve Bank of Atlanta. These numbers are slightly different for 2017. See Foster (2018).
} 


\begin{tabular}{llll}
\hline \hline Parameters & Notation & Value & Notes \\
\hline Calibrated externally & & & \\
Discount factor & $\beta$ & 0.96 & Standard in literature \\
Curvature of production & $\eta$ & 0.66 & Elasticity of commericial loans \\
Money growth rate & $\mu$ & 1.02 & $2 \%$ inflation \\
Prob of Type 1 meeting & $\alpha_{1}$ & 0.075 & Diary data \\
Prob of Type 2 meeting & $\alpha_{2}$ & 0.01 & Diary data \\
Prob of Type 3 meeting & $\alpha_{3}$ & 0.415 & Diary data \\
Cost of handling deposits & $c$ & 0.03 & Banks expenses/deposits 3\% \\
Reserve requirement & $\chi$ & 0.1 & US regulation \\
& & & \\
Calibrated internally & & & \\
Coeff. on CM consumption & $B$ & 1.74 & Money demand curve \\
Curv. of DM consumption & $\sigma$ & 0.2157 & Money demand curve \\
TFP & $A$ & 0.5024 & Deposit rate 0.05\% \\
Number of Banks & $N$ & 1 & NIM 2.98\% (Dempsey 2018) \\
\hline \hline
\end{tabular}

Table 2: Alternative Calibration Results

This shows that the parameters can be sensitive to the value of $\alpha$ s. However, it is worth noting that the benchmark calibration fits the money demand curve better.

Given the parameters are very different from the benchmark case, the effects on most equilibrium objects, which is shown in Figure 11, are different from the benchmark case. However, it is interesting to point out that it remains valid that there is a wide range of $i_{m}$ which increases lending. More specifically, if CBDC does not serve as reserves, any $i_{m} \in(0.05 \%, 1.2 \%)$ increases lending. If CBDC serves as reserves, $i_{m} \in(0 \%, 1.4 \%)$ increases lending. And the maximum increase can be around $4 \%$. This suggests that the conclusion that there is a wide range of $i_{m}$ at which CBDC can increases lending is robust to calibration method.

\section{Conclusion}

This paper develops a model with imperfect competition in the deposit market. We use the model to analyze whether introducing CBDC causes disintermediation of banks. Contrary to a common wisdom, we show that an interest-bearing CBDC 

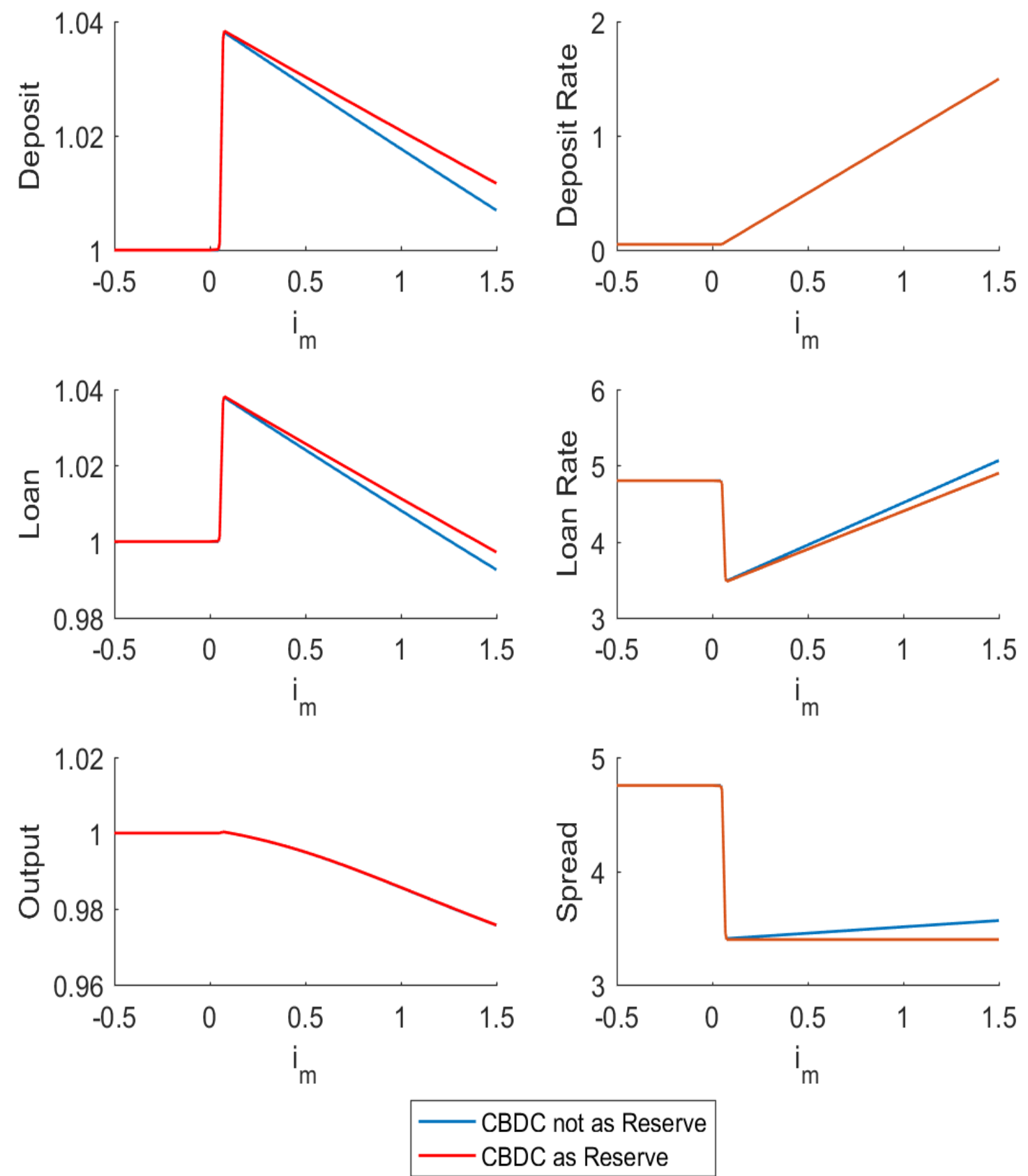

Figure 11: Effects of CBDC Rate: Alteration Calibration 
can improve bank intermediation. Intuitively, if banks have market powers, they would restrict deposit supply to lower the deposit rate. An interest-bearing CBDC reduces their market powers by setting a floor for the deposit rate, which leads to the creation of more deposits. Banks then lend more because they have more funding. This can raise total lending and output. However, more intermediation happens only if the interest rate on CBDC is set properly. In particular, if the $\mathrm{CBDC}$ rate is too low, $\mathrm{CBDC}$ does not affect the equilibrium. If the rate is too high, $\mathrm{CBDC}$ causes disintermediation. $\mathrm{CBDC}$ only helps if its interest rate is in some intermediate range.

We abstracted from many important issues such as endogenous decision of banks on the composition of both the asset side and the liability side of their balance sheets in terms of risk and maturity, and how these endogenous decisions may have macroeconomic and financial stability implications. More specifically, introducing an interest-bearing CBDC would increase banks' funding costs. On the asset side of their balance sheets, it may induce banks to take more risk to make up for their lower profit margin. This can increase the total risk of the financial system, leading to a less stable system. On the liability side, it can induce banks to switch to other sources of funding such as wholesale funding. These funding sources are generally considered less stable than deposits. Therefore, more reliance of banks on wholesale funding may increase the likelihood of runs in the wholesale market. These issues are all left for future research. 


\section{A Multiplicity under Perfect Competition}

Now we show that this model can have multiple equilibria even under perfect competition in both the deposits and loan markets. Set $\alpha_{3}=0$, which implies money and deposit dichotomize. In addition, normalize the measure of firms to be 1. Assuming $\iota$ sufficiently small, in the equilibrium, real balances is determined by

$$
\iota=\alpha_{1} \lambda(Z)
$$

Given $\psi$, the demand for deposit is determined by

$$
\psi=\alpha_{2} \beta \lambda(D)+\beta
$$

Notice that $\psi$ can never go below $\beta$, and if $\psi=\beta$, the demand for $D$ can be any value lying between $D^{*}$ and $\infty$, and if $\psi<\beta, D=\infty$.

Suppose there is a continuum of banks with measure 1 and they are price takers. Given $\psi$ and $\rho$, they solve

$$
\begin{gathered}
\max _{\ell_{j}, d_{j}}\left\{\left(1+\rho-\frac{1}{\mu}\right) \ell_{j}-\left(1+\psi c-\frac{\psi}{\mu}\right) d_{j}\right\} \\
\text { st } \quad \ell_{j} \leq(1-\chi) \psi d_{j} .
\end{gathered}
$$

As long as $\psi<(1 / \mu-c)^{-1}$, the constraint is binding and the problem reduces to

$$
\max _{d_{j}}\left\{\left[(1+\rho)(1-\chi)+\frac{\chi}{\mu}-c\right] \psi d_{j}-d_{j}\right\} .
$$

Because $\rho=\varrho(L) \equiv f^{\prime}(L)-1$, the optimization problem along with the the constraint imply

$$
\{1+\varrho[(1-\chi) \psi D]\}(1-\chi)+\frac{\chi}{\mu}-c=1 / \psi
$$

Given $\psi$, this equation defines $D$ as a function of $\psi: D=\Delta(\psi)$, which can be non-monotone depending on the curvature of the production function.

If $\psi \geq(1 / \mu-c)^{-1}$, the constraint is not binding, which means $\rho=1 / \mu-1$ and $L=\varrho^{-1}(1 / \mu-1)$. 
If $\psi>(1 / \mu-c)^{-1}, D=\infty$. If $\psi=(1 / \mu-c)^{-1}$, banks are indifferent between any amount of capital. To be consistent with market clearing $D \geq \varrho^{-1}(1 / \mu-1)(1-\chi)$. One can show that $\varrho^{-1}(1 / \mu-1)(1-\chi)=\Delta(\psi)$ if $\psi=(1 / \mu-c)^{-1}$. To summarize, the supply for deposit

$$
D=\left\{\begin{array}{cc}
\Delta(\psi) & \psi<(1 / \mu-c)^{-1} \\
\infty & \psi>(1 / \mu-c)^{-1} \\
{[\Delta(\psi), \infty)} & \psi=(1 / \mu-c)^{-1}
\end{array}\right.
$$

Any intersection between (17) and (22) determines an equilibrium.

Proposition 7 Monetary equilibrium exists iff $\iota<\alpha_{1} \lambda(0)$ and $\beta(1 / \mu-c) \leq 1$.

Proof. From (16), one can see that $Z>0$ iff $\iota<\alpha_{1} \lambda(0)$. If $\psi$ is sufficiently small, (17) defines $D=\infty$ and if $\psi$ is sufficiently large, $D$ is sufficiently small. On the other hand, (22) implies that $D$ is finite if $\psi$ is low and $D=\infty$ for $\psi$ sufficiently large. Then by continuity, these two curves has at least one intersection. Hence, at least one equilibrium exists.

In general, the equilibrium is not unique. We next use numerical examples to illustrate this. To this end, parametrize $f^{\prime}(l)=A(l+\varepsilon)^{-\xi} \mathbf{1}\{l>l\}+B l^{-\omega} \mathbf{1}\{l \leq \bar{l}\}$. Here $A, \varepsilon, \bar{l}>0$ and $\xi>1,0<\omega<1$ are parameters to choose. Then $B$ is chosen such that $f^{\prime}$ is continuous. One can integrate this function and impose $f(0)=0$ to obtain $f$. Since $f^{\prime}$ is positive and strictly decreasing, $f$ is strictly increasing and concave.

Results are shown in $\psi-D$ space in Figure 12. In all graphs, the blue curve is the deposit demand curve and the red curve is the deposit supply curve. The demand curve is monotonically decreasing while the supply curve can be monotonically increasing, or non-monotone depending on the curvature of $f$. If $f(l)=A l^{\omega}$ with $\omega<1$, the supply curve is increasing as in Figures 12(a) and 12(b). In this case, we have a unique equilibrium. If, however, $f(l)=A\left[(l+\varepsilon)^{1-\xi}-\varepsilon^{1-\xi}\right] /(1-\xi)$ with $\xi>1$ and $\varepsilon$ sufficiently small, the supply curve is decreasing for most part if 
$\psi<(1 / \mu-c)^{-1}$. This is shown in $12(\mathrm{c})$. In this case, we have three equilibrium. One has $\psi=\beta$, i.e. deposit does not carry a liquidity premium. One has $\rho=1 / \mu-1$ and $\psi=(1 / \mu-c)^{-1}$. In this case, the price for deposit is sufficiently high so that the banks are willing to take any amount of deposits and then hold them in cash reserve. Notice at this intersection, $D>\Delta(\psi)$. Consequently, the reserve requirement constraint is not binding, i.e. banks hold voluntary reserves. There is another equilibrium where the reserve requirement constraint is binding.

If $f$ is a combination of the previous two cases, the supply curve can be nonmonotone even if $\psi<(1 / \mu-c)^{-1}$ as shown in Figure $12(\mathrm{~d})$. In this case, there are two equilibria where the reserve requirement constraint is binding.

\section{B Imperfect Competition in Loan Market}

Now consider the extension that there is a competitive interbank market and the lending market features imperfect competition. We consider two cases: a Cournot lending market, and a search and matching market. In both cases, the deposit market has Cournot competition as in the previous section.

\section{B.1 Cournot Lending Market}

Now let $\rho^{B}$ be the real rate in the interbank market. Then the loan supply function

$L^{s}$ is the same as before except that now it depends on the interbank rate $\rho^{B}$. The loan makers solve

$$
\max _{\ell_{j}} f^{\prime}\left(\frac{\ell_{-j}+\ell_{j}}{N^{E}}\right) \ell_{j}-\left(1+\rho^{B}\right) \ell_{j} .
$$

To guarantee the existence of a pure strategy equilibrium given $\rho^{B}$ on the loan side, we require that

Condition $2 f^{\prime \prime}(L)+f^{\prime \prime \prime}(L) L \leq 0$. 


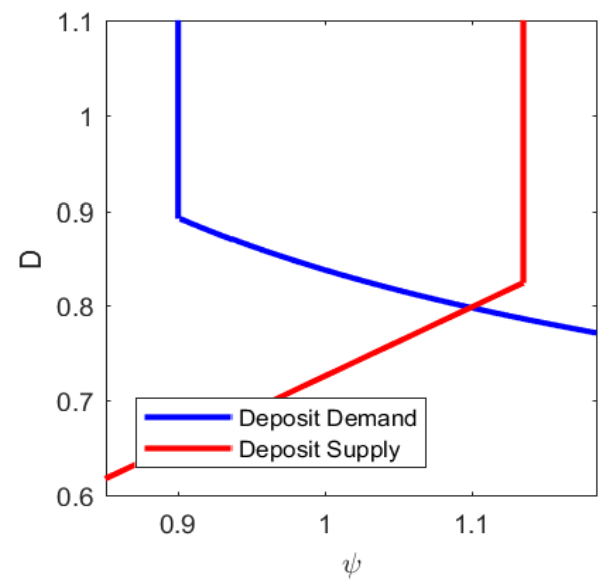

(a) Case 1

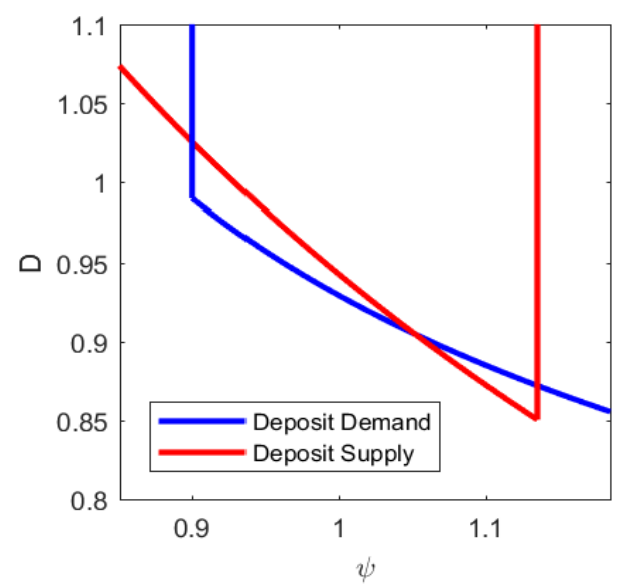

(c) Case 3

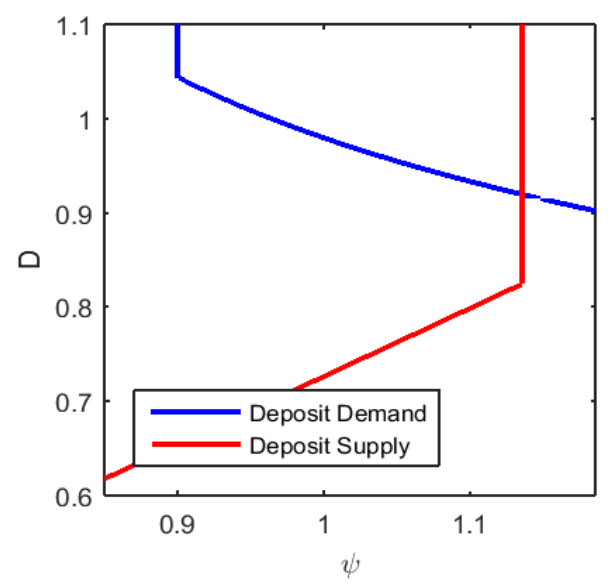

(b) Case 2

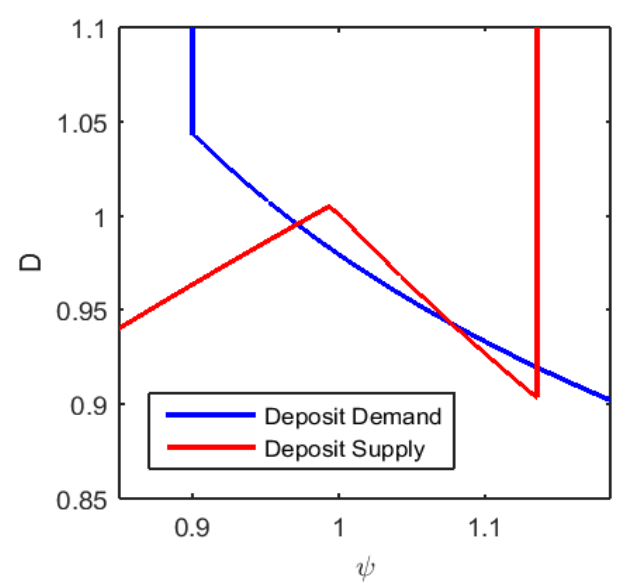

(d) Case 4

Figure 12: Equilibrium 
Then the equilibrium satisfies

$$
f^{\prime \prime}\left(\frac{L}{N^{E}}\right) \frac{L}{N^{E} N}+f^{\prime}\left(\frac{L}{N^{E}}\right)=1+\rho^{B} .
$$

This defines $L^{d}\left(\rho^{B}\right)$, which is decreasing and continuous in $\rho^{B}$. Now the equilibrium interbank market rate is determined by $L^{s}\left(\rho^{B}\right)=L^{d}\left(\rho^{B}\right)$. Then the loan rate is given by $\rho=f^{\prime}\left(L^{s}\left(\rho^{B}\right)\right)-1$.

Proposition 8 If $\iota<\bar{\iota}$ and Assumption 1 and 2 hold, there exist one or three monetary equilibria. If, in addition, $\Psi(D) D$ is increasing, the monetary equilibrium is unique.

Then comparative statics can be analyzed as before.

\section{B.2 Search for Loans}

Now suppose that each bank has a continuum of loan officers with measure $N_{l}$. They have access to a competitive interbank market and randomly search and match with firms. The matching probability is $\alpha(\lambda)$ where $\lambda=N_{f} / N_{l} N_{b}$. Upon a meeting, the loan officer bargains with the firm on the terms of loans given the interbank market rate $\rho$. The surplus is split with Kalai's bargaining solution where the firm has a bargaining power $\eta$.

$$
\begin{array}{ll} 
& \max _{\ell, p} f(\ell)-p \\
\text { st } \quad & f(\ell)-p=\eta\left[f(\ell)-\left(1+\rho^{B}\right) \ell\right] .
\end{array}
$$

In this case, $f^{\prime}(\ell)=\ell+\rho^{B}$ and $p=(1-\eta) f(\ell)+\left(1+\rho^{B}\right) \ell$. This implies the loan rate

$$
\rho^{E}=\eta \rho^{B}+(1-\eta)\left[\frac{f(\ell)}{\ell}-1\right]
$$

which is a weighted sum of the interbank market rate $\rho^{B}$ and the average investment return $f(\ell) / \ell-1$. Then the loan demand curve is

$$
L^{d}\left(\rho^{B}\right)=\alpha(\lambda) N_{l} N_{b} f^{\prime-1}\left(1+\rho^{B}\right)
$$


Then the equilibrium $\rho^{B}$ is determined in the same fashion as in the competitive loan market case. Consequently, we have

Proposition 9 If $\iota<\bar{\iota}$ and Assumption 1 holds, there exist one or three monetary equilibria. If, in addition, $\Psi(D) D$ is increasing, the monetary equilibrium is unique.

Notice that in this case, the total supply of loan is efficient given the interbank market rate $\rho^{B}$. However, the bankers get positive surplus from lending. We can then calculate the spread between the interbank rate and lending rate as $\rho^{E}-\rho^{B}=$ $(1-\eta)\left[\frac{f(\ell)}{\ell}-1-\rho^{B}\right]$.

\section{Calibration Method and Data}

The data we use are from FRED on the website of Federal Reserve Bank of st. Louis. For money demand, we use the data series of M1 to GDP ratio. For interest rate, we use the annualized three month T-bill rate. For both, we use annual data from 1959 to 2006 . We excluded three years after 9.11 and all the data after the financial crisis because the nominal rates are almost 0 in these years. FRED lists nominal interest on non-jumbo deposits after year 2009. The average annual rate on checking account is less than $0.05 \%$ and that on saving account is around $0.09 \%$. This is consistent with the Survey of Consumer Payment Choice data, where more than $80 \%$ of respondents report checking account rates below or at $0.05 \%$. We then use $0.05 \%$ in our benchmark calibration. Data on cash holding, checking account balances and fraction of online payments are all based on the 2016 Survey of Consumer Payment Choices from the Federal Reserve Bank of Atlanta.

One straightforward way to calibrate the model is to solve the whole equilibrium given the parameter and then fit the money demand curve and the deposit rates. This however can be computationally cumbersome because one need to solve the model for each data point used for the money demand and then optimize over a 
5-dimensional parameter. One key insight is that the money demand can be solved independent of the banking sector given the deposit rate. This leads to the following algorithm that greatly simplifies the calibration.

1. Fit the money demand and cash to checking account balance ratio by choosing $B, \alpha_{1}$ and $\sigma$ given $A$. More specifically,

(a) given $\alpha_{1}$, for each interest rate, calculate the steady state equilibrium using the nominal interest rate and the deposit rate. Then solve a nonlinear least squares problem over $(B, \sigma)$. The M1 to GDP ratio in the model can be calculated by $(Z+D) / \mathbf{Y}$ where

$$
\mathbf{Y}=\sum_{j=1}^{3} \alpha_{j} y_{j}+2 B+A[(1-\chi) D \Psi(D)]^{\eta}-D+(1-\chi) D \Psi(D)
$$

is the output. Here $\mathbf{Y}$ is the sum of the consumption of households in DM and CM, the consumption of bankers and entrepreneurs and the investment.

(b) set $\alpha_{1}$ to match the cash-checking ratio $5.53 \%$.

(c) update $\alpha_{1}$ and iterate a-b until converge.

2. Given $B, \alpha_{1}$ and $\sigma$, find $A$ and $N$ such that the solution of the Cournot competition leads to $0.05 \%$ rate on deposit and the net interest margin is $2.98 \%$.

3. Update $A$ and repeat 1-2 until convergence.

This greatly simplifies the calibration because we reduce a problem of 5 parameters into two problems of lower dimensions which are linked by $A$. It is also worth noting if we assume that bankers and entrepreneurs transfer all the profit back to the households, $\mathbf{Y}$ can be computed independently of $A$. In that case, we only need to do 1 and 2 once to recover all the unknown parameters. 


\section{References}

[1] D. Andolfatto (2018) "Assessing the Impact of Central Bank Digital Currency on Private Banks," mimeo.

[2] J. Barrdear, and M. Kumhof (2016) "The macroeconomics of central bank issued digital currencies," Bank of England Staff Working Paper No. 605, 2016.

[3] A. Berentsen, G. Camera, and C. Waller (2007) "Money, credit and banking," Journal of Economic theory, 135(1), 171-195.

[4] A. Berentsen and F. Schar (2018) "The case for central bank electronic money and the non-case for central bank cryptocurrencies," Federal Reserve Bank of St. Louis Review.

[5] M. Brunnermeier and D. Niepelt (2018) "On the Equivalence between Private and Public Money," mimeo.

[6] Committee on Payments and Market Infrastructures (2018) "Central Bank Digital currencies," Bank of International Settlements.

[7] Consumer Payment Research Center (2018) "Guide to the 2016 Diary of Consumer Payment Choice," Federal Reserve Bank of Boston.

[8] M. Davoodalhosseini (2018) "Central Bank Digital Currency and Monetary Policy," Bank of Canada staff working paper no. 2018-36.

[9] M. Davoodalhosseini, and F. Rivadeneyra (2018) "A Policy Framework for EMoney: A Report on Bank of Canada Research," Bank of Canada Staff Discussion Paper 2018-5.

[10] I. Dreschle, A. Savov and P. Schnabl (2017) "The Deposit Channel of Monetary Policy," Quarterly Journal of Economics 132, 1819-1976.

[11] I. Dreschle, A. Savov and P. Schnabl (2018) "Banking on Deposits: Maturity Transformation without Interest Rate Risk," mimeo.

[12] K. Dempsy (2018) "Macroprudential Capital Requirements with Non-Bank Finance," mimeo. 
[13] W. Engert and B. Fung (2017) "Central Bank Digital Currency: Motivations and Implications," Bank of Canada Staff Discussion Paper 2017-16.

[14] B. Fung and H. Halaburda (2016) "Central Bank Digital Currencies: A Framework for Assessing Why and How," Bank of Canada Staff Discussion Paper 2016-22.

[15] C. Greene and J. Stavins (2018) "The 2016 and 2017 Surveys of Consumer Payment Choice: Summary Results," Federal Reserve Bank of Atlanta Discussion Paper No. 18-3.

[16] K. Foster (2018) "Data Guide to the 2017 Diary of Consumer Payment Choice," Federal Reserve Bank of Atlanta.

[17] C. Gu, C. Monnet, E. Nosal, and R. Wright (2018) "On the Instability of Banking and Financial Intermediation," mimeo.

[18] C. M. Kahn, F. Rivadeneyra, and R. Wong (2018) "Should the central bank issue e-money," Bank of Canada staff working paper no. 2018-58.

[19] T. Keister and D. Sanches (2018) "Should Central Banks Issue Digital Currency?" mimeo.

[20] P. Kurlat (2018) "Deposit Spreads and the Welfare Cost of Inflation," mimeo.

[21] R. Lagos and R. Wright (2005) "A Unified Framework of Monetary Theory and Policy Analysis," Journal of Political Economy 113, 463-484.

[22] R. Lagos and S. Zhang (2018) "On Money As a Medium of Exchange in NearCashless Credit Economies," mimeo.

[23] T. Mancini-Griffoli, M. S. Martinez, I. A. Peria, A. Ari, J. Kiff, A. Popescu and C. Rochon (2018) "Casting Light on Central Bank Digital Currency," IMF Staff Discussion Notes No. 18-08.

[24] L. Schilling and H. Uhlig (2018) "Some Simple Bitcoin Economics," mimeo.

[25] Y. Zhu and S. Hendry (2018) "A Framework for Analyzing Monetary Policy in an Economy with E-Money", mimeo. 